\title{
Challenges in Cardiac Tissue Engineering
}

\author{
Gordana Vunjak-Novakovic, Ph.D., ${ }^{1}$ Nina Tandon, Ph.D.,, ${ }^{1,2}$ Amandine Godier, B.S., ${ }^{1}$ Robert Maidhof, M.S., \\ Anna Marsano, Ph.D., Timothy P. Martens, M.D., Ph.D., and Milica Radisic, Ph.D. ${ }^{3}$
}

Cardiac tissue engineering aims to create functional tissue constructs that can reestablish the structure and function of injured myocardium. Engineered constructs can also serve as high-fidelity models for studies of cardiac development and disease. In a general case, the biological potential of the cell-the actual "tissue engineer" - is mobilized by providing highly controllable three-dimensional environments that can mediate cell differentiation and functional assembly. For cardiac regeneration, some of the key requirements that need to be met are the selection of a human cell source, establishment of cardiac tissue matrix, electromechanical cell coupling, robust and stable contractile function, and functional vascularization. We review here the potential and challenges of cardiac tissue engineering for developing therapies that could prevent or reverse heart failure.

\section{Introduction}

$\mathbf{T}$ ISSUE ENGINEERING could dramatically change our lives and help us outlive the failure of our organs. It is becoming plausible that many of our tissues, if damaged by injury or disease, could be replaced or regenerated by functional biological grafts. Ideally, an engineered graft should reestablish normal tissue structure and persistent function across different size scales, functionally integrate with the host tissue, and remodel in response to environmental factors, growth, and aging.

It is not easy to say where the true beginnings of the field are: in the mythologies of ancient China and Greece, in the first-ever tissue culture study performed by Ross Harrison in $1907,{ }^{1}$ at the Lake Tahoe conference in 1988 when tissue engineering was "officially" established, or in the 1990s that mark the start of the fast growing stream of publicationsfrom only about a dozen in 1991 to thousands in 2008. The original definition: "Tissue Engineering is the application of principles and methods of engineering and life sciences toward fundamental understanding of structure-function relationships in normal and pathological mammalian tissues and the development of biological substitutes to restore, maintain, or improve tissue function" still reflects the unifying concept of the field. As tissue engineering is evolving, we are probably just "at the end of the beginning" of a truly exciting journey. ${ }^{2,3}$

The heart itself is a marvel of "engineering by nature," an organ of extreme structural and functional complexity, with functions vital to survival. The heart wall is composed of tightly packed myocytes and fibroblasts, with dense supporting vasculature and collagen-based extracellular matrix
(ECM). Because of the high density and high metabolic demand of the cells, myocardium consumes large amounts of oxygen and cannot tolerate hypoxia. The myocytescontractile cells of the heart-form a three-dimensional (3D) syncytium that enables propagation of electrical signals across specialized intracellular junctions, to produce mechanical contractions that pump blood forward. ${ }^{4}$

Heart is also an organ that fails beyond repair, way too often, because of the intrinsic inability of the damaged heart tissue to regenerate after injury. Heart disease and stroke, the principal components of cardiovascular disease, are the first and the third leading cause of death in the United States, accounting for nearly $40 \%$ of all deaths, more than all cancer combined. Congenital heart defects, which occur in nearly 14 of every 1000 newborn children, ${ }^{5}$ are the most common congenital defects and the leading cause of death in the first year of life.

Upon myocardial infarction, a vigorous inflammatory response is elicited, and dead cells are removed by macrophages. Over the subsequent weeks to months, fibroblasts and endothelial cells migrate and form granulation tissue that ultimately becomes a thick and stiff collagenous scar. Scar formation reduces contractile function of the heart, and leads to ventricle wall thinning and remodeling, and ultimately to heart failure. Clearly, tissue engineering could be most valuable for the reconstruction of malformed hearts in children and the regeneration of failing hearts in adults.

The three key features of native myocardium: (i) high density of myocytes and supporting cells, (ii) efficient oxygen exchange between the cells and blood, and (iii) synchronous contractions orchestrated by electrical signal propagation form a set of design requirements for engineering cardiac

\footnotetext{
${ }^{1}$ Department of Biomedical Engineering, Columbia University, New York, New York.

${ }^{2}$ Department of Electrical Engineering, The Cooper Union for the Advancement of Science and Art, New York, New York.

${ }^{3}$ Department of Chemical Engineering and Applied Chemistry, Institute of Biomaterials and Biomedical Engineering, University of Toronto, Toronto, Canada.
} 
tissue. The need to reestablish the unparalleled complexity of injured heart tissue is a major challenge for the field of cardiac tissue engineering. We review here some of the key challenges that the cardiac tissue engineering field is facing, and representative directions of the current research.

\section{Key Challenges}

For clinical utility, engineered cardiac tissue should consist of autologous or immunetolerated, phenotypically stable cardiac cell populations (myocytes, fibroblasts, vascular cells) within a native-like tissue matrix (molecular composition, structure, biomechanics). The size and thickness of an engineered graft need to be of clinically relevant size, a requirement that cannot be met without vascularization. Electromechanical coupling of the cells with the host myocardium with synchronous contractile activity and generation of contractile force are all necessary for the reestablishment of contractile function of the heart.

The utilization of advanced culture systems, new imaging strategies to monitor the progression of cardiac regeneration, and adequate animal models are among the critical tools for deriving the right populations of cells and for engineering constructs with capacity for cardiac regeneration. Beyond these largely scientific challenges, there are requirements for reproducible manufacturing of the grafts, and the regulatory and public policy issues that will need to be addressed before these therapies can be made available to patients.

\section{Challenge \#1: Selecting the right population of human cells}

For any current tissue engineering modalities that are being investigated, injection of repair cells (with our without biomaterial), implantation of a cell-based cardiac graft, or mobilization of the host cells into the site of injury, the choice of cells is central. All other components of the tissueengineered system-scaffold, culture environment, and delivery mode-essentially mediate the biological capacity of the cell to drive regeneration. In either case, the regeneration of cardiac muscle and supporting vascular compartment depends on the type and developmental stage of the cells and their capacity to drive the reestablishment of myocardial structure and function at multiple hierarchical levels.

Given the inability of intrinsic repair mechanisms to regenerate sufficient myocardium after ischemia, a great deal of effort has been spent exploring the reparative capabilities of a wide variety of exogenous stem and progenitor cells. Explosive growth in the fields of vascular and developmental biology has led to the characterization of multiple cell types with potential for supporting angiogenesis, myogenesis, or both. ${ }^{6-9}$ Figure 1 reviews the most explored human cell types for cardiac regeneration.

One obvious requirement is that of immune tolerance of the repair cells, and it should ideally be addressed by the choice of an autologous cell source. Utilization of adult stem cells from various sources has been motivated by the advantages of alleviating concerns about immune rejection or transmission of disease. Although adult stem cells were first isolated from the bone marrow, recent literature supports their presence in a variety of extramedullary organs including adipose tissue, dental pulp, circulating blood, amniotic fluid, and joint synovium. ${ }^{10-14}$ Limitations of the adult stem cells investigated thus far include the capacity of mesenchymal stem cells (MSCs) to induce vasculogenesis but not necessarily myogenesis, and the inability of skeletal myocytes for proper electrical coupling with cardiac myocytes. The mobilization of resident cardiac cells would provide an alternate path to cardiac regeneration, with the caveat that obtaining sufficient numbers of these cells remains a challenge.

Another obvious requirement is to provide sources of all cardiac cell populations-both myocytes and the supporting cardiac fibroblasts and vascular cells. Embryonic stem cells (ESCs), the only source of cells that are intrinsically cardiogenic and vasculogenic ${ }^{9,15}$ and a natural choice because of their omnipotency and essentially unlimited potential for expansion in vitro, are not autologous. Also, the use of these cells in undifferentiated state carries the risk of uncontrolled differentiation. Recent exciting developments of induced pluripotent stem (iPS) cells from various human tissues open the possibility of creating autologous embryonic-like cells for cardiac regeneration, with the caveat that the derivation of iPS cells involves, at least at this time, genetic transformation. The ongoing efforts to derive phenotypically stable cardiac and vascular cell populations from human ESCs (hESCs), in numbers sufficient for tissue engineering hold promise that the advantages of these cells will be fully utilized. ${ }^{9}$ We propose that the "conditioning" of these cells, by biophysical stimulation in 3D culture settings, may result in the stabilization and maturation of cardiac and vascular progenitors. ${ }^{16}$ For proper function, stem cells for heart regeneration need to be provided with protection and support during their delivery and integration with the host. ${ }^{17}$

It is fair to say that several promising paths toward deriving the "right" cells for cardiac repair and the right technology to utilize their potential need to be pursued until one or more of these options is translated into clinical practice.

Bone marrow-derived adult stem cells. The discovery of circulating endothelial progenitor cells, ${ }^{18}$ their mobilization in response to ischemia, ${ }^{19}$ and their isolation from human bone marrow ${ }^{20}$ have stimulated translational research of the use of bone marrow-derived elements to regenerate ischemic myocardium. The bone marrow compartment can be subdivided into two interdependent spaces-the hematopoietic cell compartment and the stroma containing MSCs. The hematopoietic compartment produces approximately 500 billion cells per day that use the bone marrow vasculature as a conduit to the systemic circulation. ${ }^{21,22}$ The stroma is composed of fibroblasts, adipocytes, nerves, and the bone marrow's vascular system that consists of a network of fenestrated, thin-walled vessels supported by the surrounding hematopoietic cells.

Hematopoietic cell compartment contains a multitude of cell types at various stages of differentiation. Cells can be harvested for transplantation either directly from a bone marrow aspirate or indirectly through peripheral blood mobilization. The latter method employs granulocyte colonystimulating factor (GCSF) to stimulate mobilization followed by apheresis to isolate peripheral blood mononuclear cells (PBMNCs) from the circulation. Density gradient separation of whole marrow aspirates is typically used to isolate bone marrow mononuclear cells (BMMNCs). Either method produces a heterogenous population of monocytes, hematopoietic stem cells, endothelial precursors, and assorted other cellular elements. ${ }^{22}$ 


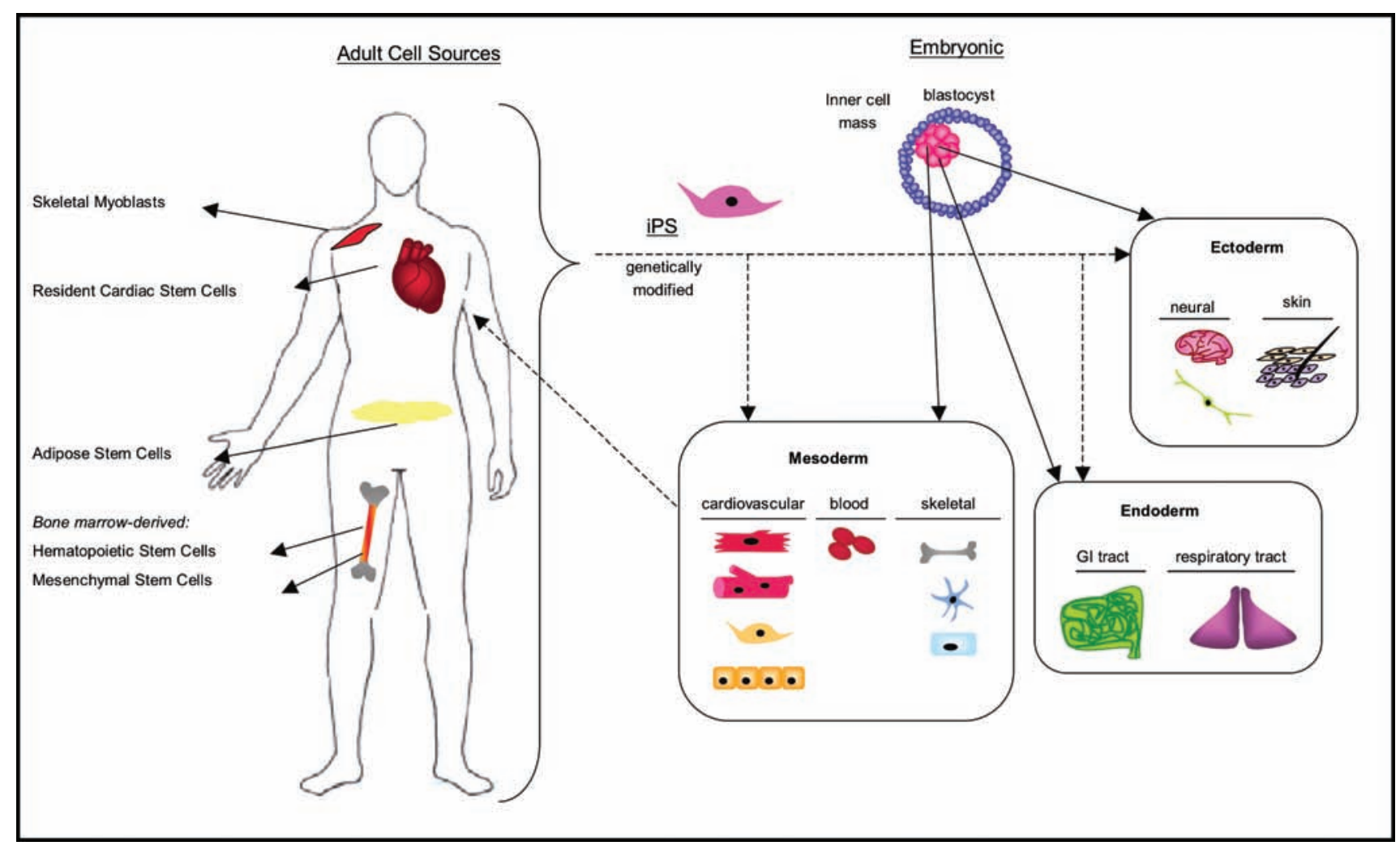

FIG. 1. Cell sources for cardiac regeneration. A variety of both adult and embryonic sources have emerged as candidates for cell therapy. Skeletal myoblasts, the first to be seen in the clinical setting, have been followed by bone marrow-derived mesenchymal and hematopoetic stem cells, and recently adipose-derived stem cells. Of these nonmyogenic somatic cells, only resident cardiac stem cells have been identified as endogenous myogenic progenitors, but their limited number eliminates them as a reliable candidate in cell therapy. Embryonic stem cells, derived from the inner cell mass of the blastocyst, give rise to all the three germ layers (endoderm, mesoderm, ectoderm) and their various cell populations. Successful derivation of cardiovascular lineages from embryonic stem cells has presented them as the most attractive myogenic source for cell therapy. Recent success with induced pluripotent stem (iPS) cells, genetically modified adult cells that display "embryoniclike" pluripotency, have hinted at their potential to differentiate into cardiovascular lineages. iPS cells represent a promising myogenic source of cardiac cells for heart therapy, eluding both ethical and immunogenic concerns, but raising questions regarding chromosomal stability. Color images available online at www.liebertonline.com/ten.

BMMNCs and PBMNCs express surface markers that can be used to isolate subpopulations of true vascular progenitor cells. One such marker, CD34, originally used to identify hematopoietic stem cells for the reconstitution of hematopoiesis after myeloablative therapy, ${ }^{23}$ is also expressed by endothelial progenitor cells both in the marrow and in the circulating blood. ${ }^{18,20}$ A second marker, AC133, corresponds to an epitope on the transmembrane protein prominin- 1 and similarly can be used to isolate hematopoietic and endothelial progenitor cells. ${ }^{24}$

Since the $\mathrm{CD}_{3}{ }^{+}$and $\mathrm{AC} 133^{+}$populations represent a minor fraction of total BMMNCs or PBMNCs, inserting an isolation step increases the homogeneity but decreases the absolute number of cells available for injection. In multiple animal models of acute and chronic myocardial ischemia, immunoselected cells from the mononuclear fraction or subsets thereof have been shown to induce angiogenesis in the infarct border zone, reduce myocyte apoptosis, and inhibit left ventricular remodeling and dilation. ${ }^{20}$ Cell differentiation into vascular structures and paracrine recruitment of endogenous progenitors were both shown to play a role in mononuclear and $\mathrm{CD} 34^{-}$mediated repair. Transdifferentia- tion into cardiac myocytes is, however, a rare event with these cell types, ${ }^{25}$ making them better suited for vasculogenesis than for myogenesis.

MSCs represent between $0.01 \%$ and $0.001 \%$ of all nucleated cells in adult human bone marrow, but can be readily expanded in culture. ${ }^{26}$ Unlike endothelial progenitors, which for the most part are lineage restricted, MSCs readily form bone, fat, cartilage, and possibly myocytes in vitro. ${ }^{27}$ In addition, a growing body of literature suggests that MSCs may be able to evade immune detection due in part to the direct inhibition of inflammation as well as a lack of cell-surface costimulatory molecules. ${ }^{28}$ These immunomodulatory properties combined with the ability to rapidly expand MSCs in culture raise the possibility of developing an off-the-shelf product for myocardial revascularization.

Preclinical data using MSCs in the acute ${ }^{29}$ and chronic $^{30}$ setting of cardiac ischemia have been promising and have led to a recently completed phase-2 human trial (www. osiristx.com/clinical_trials.php). Like their hematopoetic and endothelial precursor counterparts, MSCs are capable of stimulating angiogenesis and even arteriogenesis ${ }^{31}$ after an acute myocardial infarction. In addition, immunoselection 
before culture and expansion may allow for selection of a more homogenous population of mesenchymal progenitor cells. ${ }^{31}$ Regardless of whether MSCs do in fact transdifferentiate into cardiac muscle ${ }^{32}$ in vivo or simply fuse to existing myocytes, ${ }^{33}$ these events are sufficiently rare that significant muscle mass has not been regenerated in preclinical models.

Clinical trials with the injections of cell populations derived from bone marrow have shown only marginal increases in ejection fraction $(0-5 \%){ }^{34-37}$ The observed benefits are likely because of the paracrine factors secreted by these cells rather than the formation of new cardiomyocytes replacing those lost to ischemia. Notably, patients with larger infarcts benefited from this therapy more than patients with smaller infarcts. $^{38}$ The suggested role of bone marrow-derived cells as sources of paracrine factors, delivered continuously (by the grafted cells) or just once (if the cells are lost from the injury site), is consistent with the observed induction of vascularization and with the fact that cardiac function improved even when cell engraftment was minimal. ${ }^{6}$

Adipose-derived adult stem cells. Adipose tissue consists of mature adipocytes and the stromal vascular fraction containing vascular cells (endothelial, smooth muscle cells, and circulating blood cells), in addition to a subpopulation of multipotential stem cells termed adipose tissue-derived stem cells (ASCs) that can be isolated from the stromal vascular fraction by tissue culture plastic adhesion. Numerous reports have demonstrated the angiogenic potential of ASCs ${ }^{10}$ and, as with MSCs, exposure to 5-azacytidine (5-AZT), has led to the evidence of cardiomyocyte differentiation. ${ }^{39}$ As with MSCs, these differentiation events are, to date, rare and unpredictable, and therefore unsuitable for generating large amounts of functional muscle. However, given the preponderance of adipose tissue and its relative ease of collection, ASCs represent an excellent alternative source of vasculogenic progenitors.

Adult skeletal myoblasts. Skeletal myoblasts, precursor cells of skeletal muscle known as satellite cells, are normally found under the basal membrane of muscle fibers in a quiescent state. In response to injury, these cells have the potential to reenter cell cycle, divide, and differentiate into functional skeletal muscle. Skeletal myoblasts were the first to enter the clinical arena of cell therapy in 2000 for several reasons. ${ }^{6}$ They have high proliferative potential, yielding over a billion cells from a single biopsy, yet they are sufficiently lineage restricted to eliminate the threat of tumorigenicity. ${ }^{40}$ In addition, they are autologous and are highly resistant to ischemia. Unlike bone marrow and adiposederived elements, skeletal myoblasts are directly myogenic and contain a complete contractile apparatus.

Unfortunately, preclinical studies have called into question the ability of skeletal myoblasts to couple directly with myocardium. Early clinical data have shown an increased risk of ventricular arrhythmias after implantation. ${ }^{41}$ Examination of human pathologic specimens indicated that surviving myoblasts were often surrounded by fibrosis, ${ }^{42}$ hindering their ability to contribute to the overall pump function. Interestingly, overexpression of $\mathrm{Cx}-43$ in skeletal myocytes, by gene transfer, improved electrical coupling between the infarct bed and the surrounding borderline zone and healthy myocardium. ${ }^{43}$ Whether more sophisticated delivery techniques and/or cell culture and tissue engineering approaches can address these issues remains to be seen.

ESCs. Animal studies do not provide conclusive evidence that the populations of cells derived from bone marrow have potential to form bona fide cardiomyocytes. ${ }^{6}$ Clinical studies in humans also show that the circulating cell sources do not repopulate cardiomyocytes with appreciable frequency. ${ }^{44}$ Further, whereas the majority of adult stem cells studied to date are better suited for vasculogenesis than myogenesis, ESCs can be guided to differentiate both pathways with relative ease.

A recent study that used serum-free conditions for highefficiency differentiation of hESCs demonstrated their capacity to form bona fide cardiomyocytes and all other subpopulations of cardiovascular cells. ${ }^{9}$ Methods are now becoming available to derive human cardiomyocytes from ESCs in numbers sufficient for systematic studies of cell differentiation and maturation in vitro and regenerative capacity in vivo.

In a rodent model of cardiac ischemia, the benefits of implanting hESC-derived cardiomyocytes were better than implanting nonmyocytes, although the latter also showed improvement over injections of cell-free fluid. ${ }^{45}$ Integration was only partial as human cardiomyocytes within the mouse heart surrounded themselves by a fibrous tissue they secreted themselves. Because this isolation is not only physical but also interferes with the electrical coupling, an understanding and control of the processes involved in matrix secretion and integration with the host will be essential for avoiding the risk of arrhythmia associated with incomplete functional coupling of grafted cells.

Early in vivo studies have indicated the ability of these cells to integrate electrically with the native myocardium; ${ }^{15,46}$ however, a number of barriers remain for clinical translation. First, the use of undifferentiated ESCs is, not surprisingly, associated with teratoma formation. ${ }^{47}$ Second, implantation into humans may require immunosuppression. It is possible that terminal cell differentiation before implantation may eliminate the risk of teratoma formation. However, regulatory agencies will likely require an abundance of preclinical data before approving implantation for cardiovascular applications. The utilization of hESCs for heart regeneration will require further progress toward (i) avoiding the formation of teratomas (also a risk factor for iPS cells), (ii) avoiding the immune response of the host, (iii) development of cell culture protocols that minimize the use of any animal products, and (iv) improved control over retention, survival, and function of implanted cells.

iPS cells. iPS cells are an emerging technology that may address some of the immunologic concerns associated with the use of ESCs. By introducing a set of transcription factors linked to pluripotency, terminally differentiated cells such as dermal fibroblasts and mesenchymal stem can be reprogrammed to behave like ESCs. ${ }^{48-50}$ This allows for the creation and expansion of patient-specific cell lines that could be used for autologous reimplantation as well as to study patient-specific disease states in vitro. The need for retroviral vectors during reprogramming as well as karyotypic abnormalities associated with the process may limit clinical application. The generation of iPS cells by virus-independent 
protein transduction mechanisms is under development. ${ }^{51}$ Notably, the efficacy of all the current iPS derivation protocols is rather low. Nevertheless, iPS cells represent a novel myogenic alternative to standard hESC culture or nuclear transfer-based techniques.

Resident cardiac stem cells. A number of groups have worked toward isolating resident cardiac stem cells from the developing or adult heart with varying degrees of success. Chien and colleagues have identified a subpopulation of islet1-positive cells in the developing heart that give rise to both vascular structures and predominantly right-sided myocytes. ${ }^{52}$ Although extensively characterized, these islet1positive cells also need to be expanded to produce clinically relevant numbers. Marban and colleagues have utilized a different approach to generate cardiospheres from endomyocardial biopsies. Cardiosphere-derived cells express a mixture of stem and contractile proteins and have been shown to engraft in a mouse infarct model. ${ }^{53}$ Again, reliable production of cells in sufficient quantities remains a challenge.

In summary, the prospect of delivering cells to repopulate the heart and restore its function has resulted in many clinical trials, with varied results. Cell therapies currently under investigation (Fig. 1) involve delivery of precursor cells (both embryonic and adult), in hope that the implanted cells will proliferate, differentiate, and functionally couple in vivo, or act as "factories of factors" recruiting native progenitor cells. $^{54}$

Current clinical trials use mostly nonmyogenic cell sources that contribute to vascularization but do not give rise to new cardiomyocytes. $^{6}$ hESC-derived cardiomyocytes have been considered the only source of exogenous myogenic cells for cardiac muscle replacement. ${ }^{9,55,56}$ Just very recently the iPS cells, derived by reprogramming of adult human somatic cells, are emerging as another source of cells with the capacity to form muscle progenitors. ${ }^{48-50}$ While muscle replacement may restore the whole heart syncytium, nonmyogenic cells contribute to vasculogenesis and activate host repopulation of ischemic tissue through paracrine effects. Both the adult and embryonic cell types are thus of interest for developing therapeutic options that would result in macroscopic and long-term improvements in heart function and restore functionally coupled myocardial mass.

\section{Challenge \#2: Establishing cardiac-like tissue matrix}

Cells respond to their environment, and one of the key regulatory components of cell behavior in each of the possible scenarios of heart regeneration-in vitro cultivation of engineered constructs, cell delivery into the heart, implantation of engineered constructs over the injury site-is the ECM.

For "normal" function, the repair cells need a normal matrix, with the cardiac-like molecular composition, structure, and mechanical properties. A preformed matrix can be used as a scaffold to seed the cells and create cardiac tissue constructs in vitro, or the cells can be induced to form their own matrix, or the two approaches can be combined. One can start from the decellularized matrix of the heart, populate it with cardiogenic cells, and induce functional assembly of the cells in vitro. ${ }^{57}$

Another strategy is to custom design a synthetic biomaterial to mimic the hierarchical structure and mechanical properties of the heart matrix (e.g., using channeled, highly porous elastomers with elastic moduli matching those of the native heart matrix, with or without added hydrogel component) and use it as a scaffold for the formation of a contractile cardiac patch. ${ }^{58}$ Alternatively, cardiac cells can be cultured in a hydrogel and allowed to produce and assemble their own matrix. ${ }^{59}$ Finally, cells can be delivered into the heart, using a hydrogel to localize the cells at the site of injury and condition their environment, ${ }^{31}$ and allowed to elaborate their matrix while coupling with the host tissue.

Two features are shared by all these approaches: the entire milieu of the ECM is important (molecular composition, hierarchical structure, and biomechanics), and the cells need to remodel the initial matrix and to gradually replace it with its own matrix (the process enhanced by the high density of cardiac cell populations).

Challenges include the selection between a simple hydrogel and a cardiac tissue matrix of high fidelity, and between native and synthetic materials, determination of how much matrix needs to be reconstituted in vitro, and scaffold designs that support cell coupling and assembly (functional groups, low stiffness) and vascularization (arrays of channels).

Native tissue matrix as well as the scaffolding material serve as a structural and informational "template" for cell attachment and tissue formation, and provide numerous chemical and biophysical cues that fundamentally determine cell behavior. In a native tissue, the ECM contains proteins, such as collagens, polysaccharides, and water, and has a structure that is dependent on the location and function of the tissue. Factors such as ECM mechanics and cell shape play a role in stem-cell differentiation and can be engineered into synthetic matrices for directed differentiation.

Mimicking the structure and stiffness of native tissue matrix. Biomaterial scaffolds, designed to serve as a substitute of the native matrix, are available to tissue engineers in many different forms. ${ }^{60}$ Some of the most common categories are porous, fibrous, and hydrogel scaffolds-like the many different tissue structures they are made to resemble. ${ }^{61}$ For example, porous scaffolds provide macroscopic voids for the migration and infiltration of cells. In contrast, fibrous scaffolds can be fabricated on a scale that mimics the hierarchy of the native ECM and used to control cellular alignment. ${ }^{62}$

The fabrication technique can produce structures that exhibit a wide range of mechanical properties with elastic moduli from the $\mathrm{Pa}$ to the GPa range. Human MSCs were shown to exhibit lineage specification depending on the substrate mechanics, which correlated with the in vivo matrix elasticity (8-17 kPa for muscle) in the absence of any additional inducing actors. ${ }^{63}$ The stem cells are thought to "pull" on the matrix and generate signals and responses based on this force.

Notably, the stiffness of infarcted myocardial tissue changes with time from soft to rigid, as the collagenous scar forms. Therefore, the responses of implanted or recruited cells in the infarcted heart will depend on the stiffness of the infarct bed, which in turn depends on time postinfarction. ${ }^{14}$ Presumably, the changing stiffness of the infarct bed, along with multiple biochemical factors associated with the progression of myocardial remodeling, is one of the critical factors of the recovery of the contractile functionality of the ventricle by transplanted cells. Studies of cardiac tissue 
development on scaffolds with controllable stiffnesses will be instrumental in developing strategies for the regeneration of infarcted heart.

Native or synthetic material? A second decision in scaffold selection is the choice between natural and synthetic materials. ${ }^{64}$ Natural materials are able to provide signals to cells by mechanisms such as surface receptor interactions, by uptake, and by degradation by cell-instructive enzymes. However, natural scaffolds may be difficult to process without disrupting a potentially important hierarchical structure. Also, hydrogels formed from natural materials generally have poor mechanical properties and may also have a potential for immune response depending on the source of the material. Synthetic biomaterials have a wide range of properties that may be obtained and customized with respect to mechanics, chemistry, and degradation, but may be limited in functional cellular interactions unless they are modified with adhesion peptides or designed to release biological molecules.

Incorporation of regulatory molecules. Scaffolds can also be used for controllable delivery of cytokines or other regulatory factors to cells in a construct. A dextran-based hydrogel with immobilized arg-gly-asp (RGD) peptides and microencapsulated vascular endothelial growth factor was shown to markedly increase the fraction of encapsulated hESCs expressing vascular endothelial growth factor receptor KDR/ Flk-1- up to 20-fold compared with spontaneously differentiated embryoid bodies. ${ }^{65}$ By patterning bioactive molecules onto scaffolds or delivering controlled gradients via bioreactors, one can have spatial control over cell differentiation and ultimately design 3D cardiac constructs for in vitro and in vivo use.

Biomaterials for cell delivery into the heart. The past decade's burst in cell therapy clinical trials has resulted in a multitude of reports ranging from high expectations to modest questioning of the efficacy of cell therapy for cardiovascular disease. The perception is, however, that cell therapy would greatly benefit from improvements in the techniques of cell delivery and an improved understanding of mechanisms driving heart repair. A lack of standardization across clinical trials-because of variable cell sources and preparations, delivery methods, target patient population, time points, and functional readouts-has only added to the inherent variability, making a comprehensive crossstudy comparison rather difficult. To move forward, we need to develop new technologies that can address the challenges and limitations of the current preclinical trials.

Cell injection: The administration of cell suspensions in fluid via a syringe or catheter-results in massive attrition after injection, by processes that occur almost immediately, and irrespective of cell type or formulation, delivery mode, and disease state. These processes occur before the vascular supply can be established and integration with the host cells can occur. The capacity of the heart to retain implanted cells for even $24 \mathrm{~h}$ is rather small, ${ }^{66}$ and local barriers of cell survival and function beyond this time point are substantial. Survival of "naked" cells in the hostile environment of an acute or chronic infarct is a major challenge.

Several possibilities have been identified for improving cell engraftment and maximizing the potential of cells to mediate heart regeneration. One reported approach identified the addition of prosurvival factors into the cell suspension as a method to substantially improve the survival of transplanted cardiomyocytes. ${ }^{55}$ A solution for improved cell retention, just starting to be explored in the lab settings, is the use of catheter-based hydrogel cell delivery, which builds on existing delivery methods used in the clinic. Hydrogels, delivered as a fluid phase suspension via catheter, slowly polymerize during the trajectory to the target tissue, polymerizing and entrapping cells in situ. With already extensive use and demonstrated safety of catheter-based cell delivery, ${ }^{67}$ the addition of a delivery vehicle offers a possibility for improving engraftment.

Hydrogels offer additional distinct advantages of customization using growth factors to specifically enhance the vasculogenic or myogenic capacity of encapsulated cells, ${ }^{65}$ while physically shielding cells from the harsh ischemic environment, as they mediate repair. Although this option provides for a near-term solution to improve cell retention in the heart, it can be further advanced to mediate the effects of the microenvironment in situ.

Cells or engineered tissue? The last few years have seen increased focus on cell transplantation modalities that would enable quantitative studies of cell differentiation and coupling, and help determine regenerative capacity of various cell types and preparations. Most cells, and stem cells in particular, require protection during their delivery into the infarct bed. ${ }^{17}$ The clinical potential of stem cell-based therapies could be realized by providing support for these cells during and after implantation, in a way that promotes cell survival, differentiation, and the establishment of functional connections with the host tissue. Figure 2 schematically presents three principal approaches to cell delivery to the heart currently under investigation: (i) injection or infusion of cell suspension, (ii) injection of cell suspension in a hydrogel that polymerizes in situ, and (iii) implantation of a cardiac tissue "patch" over the infarct bed. The disease or injury in question will probably determine whether injection of cells or grafting tissue-engineered constructs is the preferred choice.

When considering a tissue engineering strategy for patients with terminal heart failure, at least two scenarios can be envisioned. A simpler one is to place a patch of engineered heart muscle over the injury site. A more elaborated one is to excise nonfunctioning myocardium and replace it with an engineered heart muscle construct. The latter approach requires high mechanical stability of the patch to withstand systolic pressure and this may be quite difficult to achieve. Thus, adding tissue-engineered patches to the heart rather than replacing diseased parts is likely the more realistic perspective at this point.

\section{Challenge \#3: Construct size and the need for vascularization}

For clinical utility, an engineered cardiac patch should have an area of $10-50 \mathrm{~cm}^{2}$ and a thickness of several millimeters. Several tissue engineering technologies are able to create a cardiac patch of a large enough surface area, but engineering viable millimeters thick cardiac constructs and their integration to the vascular supply of the host remains major challenges. 


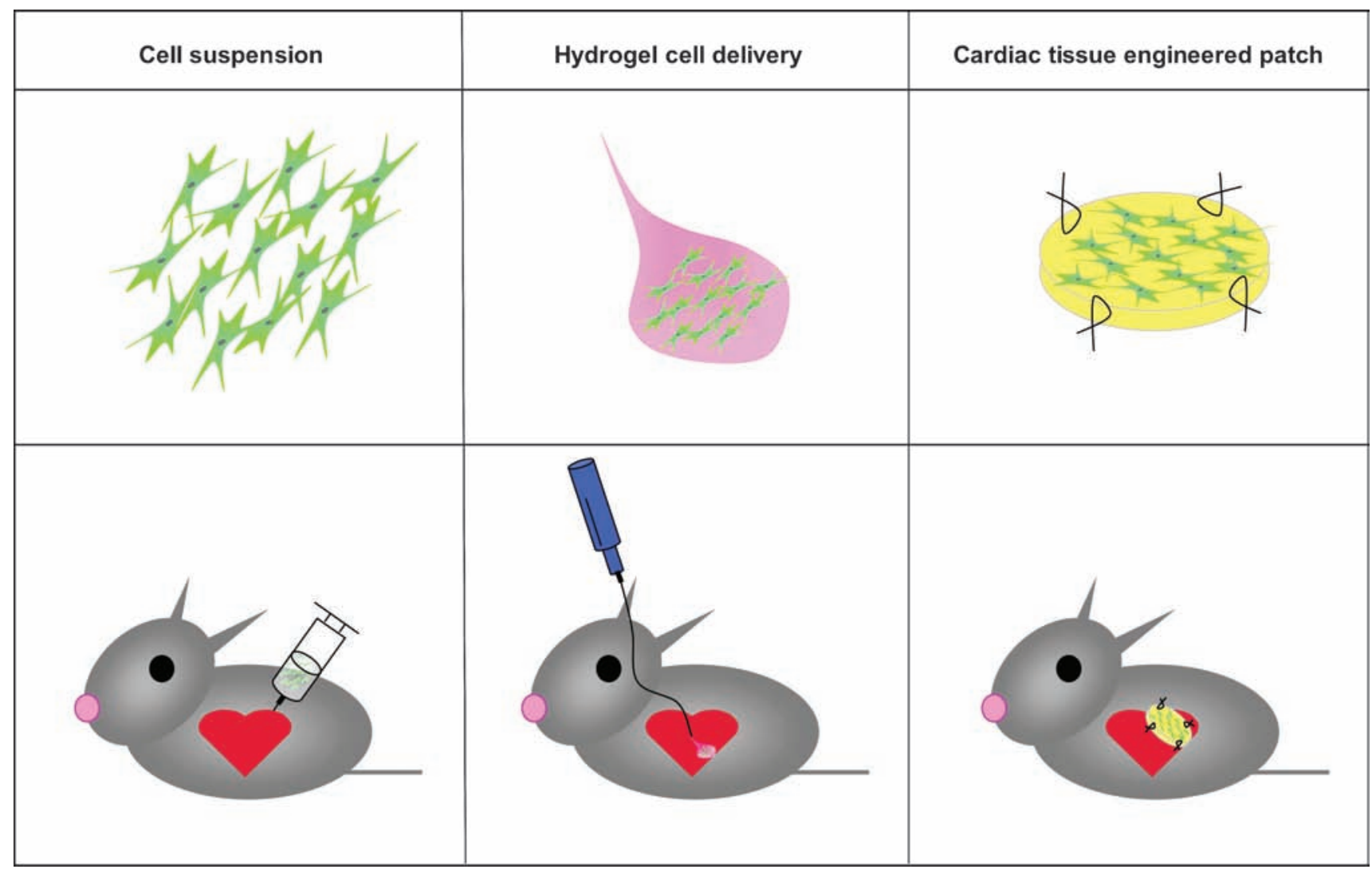

FIG. 2. Delivery to the heart-cells or tissues? Existing administration of liquid-phase cell suspensions suffers from low engraftment and cell survival. Alternative solutions for cell delivery are investigated to provide control over cell retention in the injury site, survival, and coupling with the host cells. Hydrogel cell delivery via catheters may aid to cell retention and also provide environmental conditioning via hydrogel design. Tissue engineering of a contractile cardiac patch seeks to deliver cells within a tissue-like microenvironment with immediate function and a capacity for vascular and electromechanical integration with the heart. Color images available online at www.liebertonline.com/ten.

Clearly, the single most important factor limiting the thickness of a tissue construct that can be engineered in vitro and survive in vivo is the control of oxygen supply in the immediate cell microenvironment. Diffusion alone, a mechanism relied upon in most currently used tissue culture systems, can maintain the viability of cardiac cells only within a thin layer in immediate contact with the culture medium (up to $100 \mu \mathrm{m}$ thick, depending on cell density ${ }^{68}$ ). Even when tissue constructs are cultured in systems with medium convection around tissue constructs-spinner flasks, rotating bioreactors, and orbitally mixed dishes ${ }^{69,70}$ diffusion remains the controlling mechanism of oxygen exchange inside tissue constructs.

Many tissue engineering approaches have attempted to overcome the diffusional limitation of oxygen transport in one way or another. One notable example is the work by Kofidis et al. ${ }^{71}$ that provided pulsatile flow around cardiomyocytes encapsulated in fibrin glue around a rat artery. Another is by Dvir et al. ${ }^{72,73}$ who developed a perfusion bioreactor that employs a distributing mesh upstream from the construct to provide homogeneous fluid flow and maximum exposure to perfusing medium, resulting in somewhat increased cell viability because of the convective supply of oxygen. ${ }^{72,73}$ The Eschenhagen group has minimized the intrinsic diffusional constraints using a loose network of engineered loops as a cardiac graft. ${ }^{74}$ Our group has implemented the in vivo-like mechanisms of convective-diffusive oxygen transport, by perfusion of culture medium through the cultured constructs. ${ }^{58,68,75-77}$ Cells were seeded into porous scaffolds with arrays of channels (designed to shorten diffusional distances, provide a separate compartment for fluid flow, and serve as precursors of future blood vessels) and cultured in medium supplemented with an oxygen carrier (to further increase the oxygen carrying capacity). Both the perfusion and supplementation of an oxygen carrier improved the viability and differentiation of cultured cells and enabled the formation of compact layers of viable cells around the channels. ${ }^{58}$

However, perfusion alone cannot substitute for vascularization. It is debatable which extent of vascularization needs to be provided before implantation (channels only, ${ }^{78}$ or channels lined with vascular cells, or primitive blood vessels formed by the cells ${ }^{15,74}$ ). Also, it is not entirely clear which aspects of vascularization are needed early on: structural design that favors the infiltration of host cells and the connections with vascular supply (channels, highly porous structures), coculture of vascular and cardiac cells that is important for paracrine signaling, ${ }^{15,79}$ or the immobilization of angiogenic growth factors into scaffolds. ${ }^{80}$

Finally, any scenario for implantation of an engineered tissue graft needs to provide a means for effective and timely 
connection with the host blood supply. This is considered a major challenge of cardiac tissue engineering and the solution is still not on the horizon. However, there are several interesting findings that may provide cues for the development of approaches that could ultimately address the challenges of functional vascularization. Early during embryogenesis, the mammalian heart is largely avascular, ${ }^{81}$ and the blood vessels form simultaneously with heart development to establish the impressive vascular density in the adult heart with capillary distances of only $\sim 20 \mu \mathrm{m} .{ }^{82}$

Interestingly, Eschenhagen and colleagues observed that their engineered constructs, containing strands of cardiac muscle that were small enough to remain viable in nonperfused culture, survived when implanted into the avascular environment of the infarct bed and quickly vascularized. ${ }^{74}$ The size of viable and compact muscle units increased along with vascularization in vivo, suggesting that a gradual increase in the construct size is necessary and that this increase can only occur in parallel with vascularization. Other studies showed that the diffusional limitations encountered in vitro are worsened after implantation because of the scarce vascularization of ischemic areas. ${ }^{83}$ Shimizu et al. ${ }^{84}$ performed repeated subcutaneous implantations of triple-layered sheets of cells, to support the fusion of multilayered sheets by inducing vascularization of each graft. Implantation of constructs over surgically connectable arteries and veins ${ }^{84}$ and the use of a vascularized tissue engineering chamber implanted into the groin region of rat $^{85}$ all showed enhanced vascularization.

The state of the art in the field is that vascularization is considered essential for the implementation of cardiac grafts, 86 with different approaches pursued by different groups.

\section{Challenge \#4: Electromechanical function}

A hallmark of functional myocardium is its ability to propagate electrical impulses and to respond to these impulses by synchronized contractions that generate forces for pumping blood. An engineered cardiac construct, or injected cells, should connect to the electrical synctium of the existing myocardium, rather than having spontaneous contractile activity. Cardiac constructs engineered with electrical field stimulation or mechanical stretch exhibited propagation velocities approaching those in the native heart ${ }^{74,87}$ with a conduction velocity that was twice as high in the direction of stimulation than in the transverse direction. ${ }^{74,88}$ Notably, spontaneous cell contractions diminished during cultivation, and instead the constructs developed contractile function in response to external electrical stimuli. ${ }^{88}$ Conditioning by dynamic mechanical stretch resulted in the development of significant contractile force that was lower than in the adult heart but consistent with the smaller size and density of cardiac myocytes. ${ }^{74}$

For both the mechanical and electrical stimulation regimes, the development of contractile function was associated with cell elongation and orientation, organization of Connexin-43, and the ultrastructural features characteristic for well-differentiated striated myocardium. ${ }^{74,89}$ Also, both groups observed that cell coculture, established either by combining populations of cardiac myocytes with supporting cells-fibroblasts and vascular cells ${ }^{90}$ - or using unsorted heart cells ${ }^{86}$ further improved the contractile function.
In contrast to the injected cells, an engineered cardiac patch would instantly add to the contractile function of the treated heart, assuming that functional connections are established. One of the key challenges is certainly a fair and accurate assessment of electromechanical integration between the engineered constructs and host myocardium. Histological identification of proteins involved in establishing cell contacts cannot be considered as evidence of coupling. Even in cases where undelayed impulse propagation can be demonstrated (e.g., using optical mapping), it is difficult to exclude the possibility that signal propagation is based on electronic contact. ${ }^{91}$

The choice of animal models is another significant factor, given that the rodent models, most frequently used for a variety of good reasons, are not well suited for the studies of electromechanical coupling and the risk of arrhythmia, because of the major differences in the electrical properties between the rodent and human cells. ${ }^{92}$ Also, the inflammatory response and scar formation might be essential for mediating angiogenesis, recruitment of host cells, and the overall process of regeneration. ${ }^{93}$

As with most engineered tissues, the establishment of cardiac tissue function is rather difficult to achieve and rigorously evaluate. Also, like in almost all other applications involving biological grafts, an obvious and unanswered question is "How much is enough?" in terms of functional tissue outcomes, and which properties are more important than other, should one need to prioritize.

\section{Challenge \#5: Advanced culture platforms}

Extensive studies in vitro do not necessarily predict outcomes in animal models. To mediate this transition, tissue engineers have developed biomimetic systems that seek to recapitulate the in vivo environment in a controllable manner. Moving from small to large animal models, and eventually to human clinical trials, is associated with huge biological complexity that cannot be overcome if we make a transition between the "flat biology" of conventional cell culture and whole animal models. Further advances in the application of stem cells require a new generation of culture systems that would more authentically represent the actual cell/tissue environment and be more predictive of cellular responses in vivo. ${ }^{16}$

During development, tissues emerge from coordinated sequences of cell proliferation, differentiation, and functional assembly that are orchestrated by factors originating from the surrounding cells, matrix, and the external environment. Likewise, during the repair/regeneration of adult tissues, cells respond to the entire milieu of injury or disease. Standard culture systems lack the cell/matrix surrounding and the critically important interplay of molecular and physical factors. Cell behavior in these settings will therefore differ from that seen in vivo, and the utility of data obtained for any situation of interest will be rather limited. Tissue engineering technologies are considered crucial for moving away from studies of single cells toward the analysis of physiologic endpoints. ${ }^{94}$

During development, highly coordinated sequences of cell renewal, differentiation, and assembly give rise to the forming tissues and organs in an organism. Spatial and temporal gradients of regulatory factors at the level of the 
cell are necessary to regulate cell function in a developing and adult organism. To study the function and exploit the benefits of these factors in vitro, techniques of tissue engineering have become increasingly focused on providing cells with microenvironments similar to those found in vivo. To take full advantage of the potential uses of stem cells, at least some of the aspects of the dynamic 3D environments that are associated with their renewal, differentiation, and assembly in native tissues need to be reconstructed. One challenge we face today is to establish effective correspondence between the in vitro and in vivo studies, through the utilization of advanced technologies that combine tight control of microenvironmental factors with the biological fidelity normally seen in whole animals.

Biological principles and engineering design. Stem cells react to even minute changes in their environment, and the environment has been recognized as a key regulator of cell survival, behavior, and differentiation capacity. ${ }^{6,45,95-98}$ If not conditioned for the environment they will encounter in vivothe physical and biochemical signals as well as the hypoxic environment of ischemic tissue-the repair cells are less likely to adapt to drastically changed conditions in their new environment and instead fail to differentiate and secrete key factors, or die. This appears to be the case for repair cells from both myogenic and nonmyogenic sources. ${ }^{6,45}$

To provide an appropriate microenvironment to condition cells for repair, an alternative cell delivery method could be to deliver cells within a scaffolding material. Stem cells alone, without a supporting structure, will probably not be sufficient for most therapies. The factors associated with the ECM they reside in are one of the key directions of the ongoing research. The determination and control of cell-scaffold interactions are critical to ensure that the material and host live together and function correctly.

A common approach adopted in many techniques of tissue engineering is to culture cells on a biomaterial scaffold and regulate the environmental conditions via bioreactors toward reconstructing a functional tissue. With this approach, one can attempt to manipulate the cells' responses in predictable ways by utilizing the same complex factors known to direct development and remodeling in vivo. Scaffolds and bioreactors are used to provide cytokines (diffusing, immobilized, presented to the cells in form of gradients in space or time), matrix properties (architecture, stiffness), and biophysical factors (hydrodynamic shear, mechanical stretch, electrical signals). Since the cues presented to the cells are the principal determinants of cell phenotype and function, the design of tissue engineering systems is necessarily inspired by biology in either the adult or developing organism.

Bioreactors for environmental control and biophysical signaling. A bioreactor is typically defined as a device that provides tight control of environmental conditions (such as oxygen/nutrient transport) and the application of molecular and physical regulatory factors, to influence cell culture processes (such as cell expansion, differentiation, and tissue formation on 3D scaffolds). A bioreactor should ideally provide a native-like cell environment and address the specific requirements for the tissue of interest. Therefore, bioreactors are often custom designed to recapitulate the specific mechanisms of nutrient transfer and specific biophysical signals in each type of native tissue.

Mass transport: Nutrient exchange is one of the most critical factors for cell survival and function. Healthy cardiac tissue contains dense vascular network that supports the compact and highly metabolically active myocardium. Diffusional gradients of oxygen can reduce the formation of viable tissue to an outer layer that is only $\sim 100 \mu \mathrm{m}$ thick (corresponding to the penetration depth of oxygen), with apoptotic and dead cells in the bulk of the construct. ${ }^{99}$ Bioreactors that perfuse oxygen-rich culture medium through the cultured tissue have been used to engineer thick and compact constructs consisting of viable and welldifferentiated cells. ${ }^{89,100}$

Oxygen supply also plays a critical role in the survival and differentiation of stem cells. Even a very simple system, a stirred flask with perfusion of culture medium and monitoring of oxygen levels, enhanced the yield and viability of cardiomyocytes derived from ESCs encapsulated in agarose gel microdrops. ${ }^{16,101-103}$

Mechanical conditioning: Mechanical stimuli are major regulators of the development and function of many tissue types, including the myocardium. Mechanical forces regulate cell physiology under normal and pathological conditions and influence the direction of stem-cell differentiation. For example, native blood vessels develop and function within a complex mechanical environment that involves hydrodynamic shear, luminal pressure, circumferential stretch, and longitudinal stretch, necessitating the development of bioreactors with mechanical stimulation for engineered blood vessels. ${ }^{104}$ In other studies, human MSCs were grown on a silicone tube that combined the application of flow shear, radial stretch, and pulsatile pressure to induce the expression of endothelial cell and smooth muscle cell markers. ${ }^{105}$

Areas of application: Three areas of bioreactor applications are of great interest:

- Tissue engineering of functional human grafts for regenerative medicine. Examples include the engineering of tissue grafts with gradients of molecular, structural, and mechanical properties that involve the utilization of a new generation of biological scaffolds and bioreactors with multiparametric stimulation.

- In vitro models of disease. Engineered tissues, in conjunction with microtechnologies, can be used as experimental tools to study the progression of disease, the effects and mechanisms of drug action, and thereby facilitate therapeutic discovery.

- Fundamental research of human stem cells. Engineered "biomimetic" environments that allow stem cells to be measured and physically manipulated in unprecedented ways are now replacing the simple but deficient environments of culture dishes. ${ }^{16,106}$ With the aid of functional imaging (on molecular, cellular, and tissue levels, in vitro and in vivo), we can envision an entirely new kind of stem-cell science.

Designing in vivo-like experimental models: Recent advances in scaffold and bioreactor designs have enabled simultaneous control over multiple molecular and physical regulatory signals within biologically sound culture environments. Different designs are currently being explored based on the principles learned from the cellular microenvironment of 
the tissue of interest. In general, the use of 3D scaffolds and bioreactors instead of two-dimensional (2D) settings of classical Petri dishes enables experimentation under conditions that can be tightly controlled and adjusted to match those in vivo. ${ }^{16}$

Figure 3 summarizes the envisioned scenario of studying stem cells under conditions predictive of their behavior in vivo. Biomaterial scaffold (in form of a hydrogel, native tissue matrix, or a synthetic porous structure designed to mimic native matrix) provides the cells with a 3D environment in which they reside surrounded by other cells and matrix molecules. Scaffolds need to be designed to mimic the matrix in which the cells reside-during development, tissue regeneration, or in the context of a disease. The bioreactor is in turn designed to provide multiple functions, some of which are universal (environmental control) and some are tissue specific (molecular and physical signals). For engineering cardiac tissue, the key requirements include the efficient supply of oxygen, cascades of molecular factors (the combinations and timing of which are critical to the renewal and differentiation of stem cells), and the provision of electrical and mechanical signals (which play major roles in the functional assembly and coupling of cardiac cells and their progenitors).

The basic methods of 3D stem-cell culture are well established, but the challenge of providing conditions predictive of cell behavior in vivo remains. By carefully studying various characteristics of the native (developing or adult) cell environment and applying them during 3D culture, one can begin to develop differentiated, functional tissues from stemcell sources.

\section{Challenge \#6: Imaging}

Imaging is another area of intensive research and high potential impact that is motivated by the need to investigate cell fate, survival, and differentiation-in vitro and in vivo- in real time and on a long term. ${ }^{107,108}$ Methods for tracking cell movement, survival, and differentiation in 3D tissues and animal models with the accuracy of standard 2D assays are yet to be developed. Requirements of such systems are long-term visualization, single-cell resolution, and in-depth and noninvasive imaging modalities. Numerous translational studies have used cell ${ }^{9}$ and molecular markers ${ }^{109}$ to track in vivo developments, but these methods may prove unsuitable for clinical use for a variety of reasons, including extended exposure to potentially harmful imaging sources, adverse or confounding effects of cell and molecular tags, and the inability to image resolutely beyond several hundred micrometer distances. ${ }^{109,110}$

Advances in molecular imaging technologies, especially with markers that not only detect presence but also indicate the differentiation state and function of repair cells, will be hugely influential in bringing regenerative medicine to the next level of understanding.

\section{Current Concepts in Cardiac Tissue Engineering}

Cardiac tissue engineering aims to create tissue constructs that are thick and compact, contain physiologic densities of metabolically active cardiac cell populations, and contract synchronously in response to electrical stimulation with an appropriate amount of force (Figure 4). For implantation, the construct should be either prevascularized or be able to establish functional vasculature quickly. The most difficult requirements are probably related to the establishment of blood flow and to integration and electromechanical coupling with the host tissue.

In native myocardium, cardiac myocytes form a 3D synctium that enables propagation of electrical signals across specialized intracellular junctions to produce coordinated mechanical contractions that pump blood forward. ${ }^{4}$ The
FIG. 3. The basic methods of three-dimensional (3D) stemcell culture (cell seeding onto 3D scaffolds and bioreactor culture) are well established, but the challenge of studying stem cells under conditions predictive of their behavior in vivo remains. By carefully studying various characteristics of the native (developing or adult) cell environment and applying them during 3D culture (with scaffolds and/or bioreactors), one can begin to develop differentiated, functional tissues from human stem-cell sources. Color images available online at www.liebertonline.com/ten.

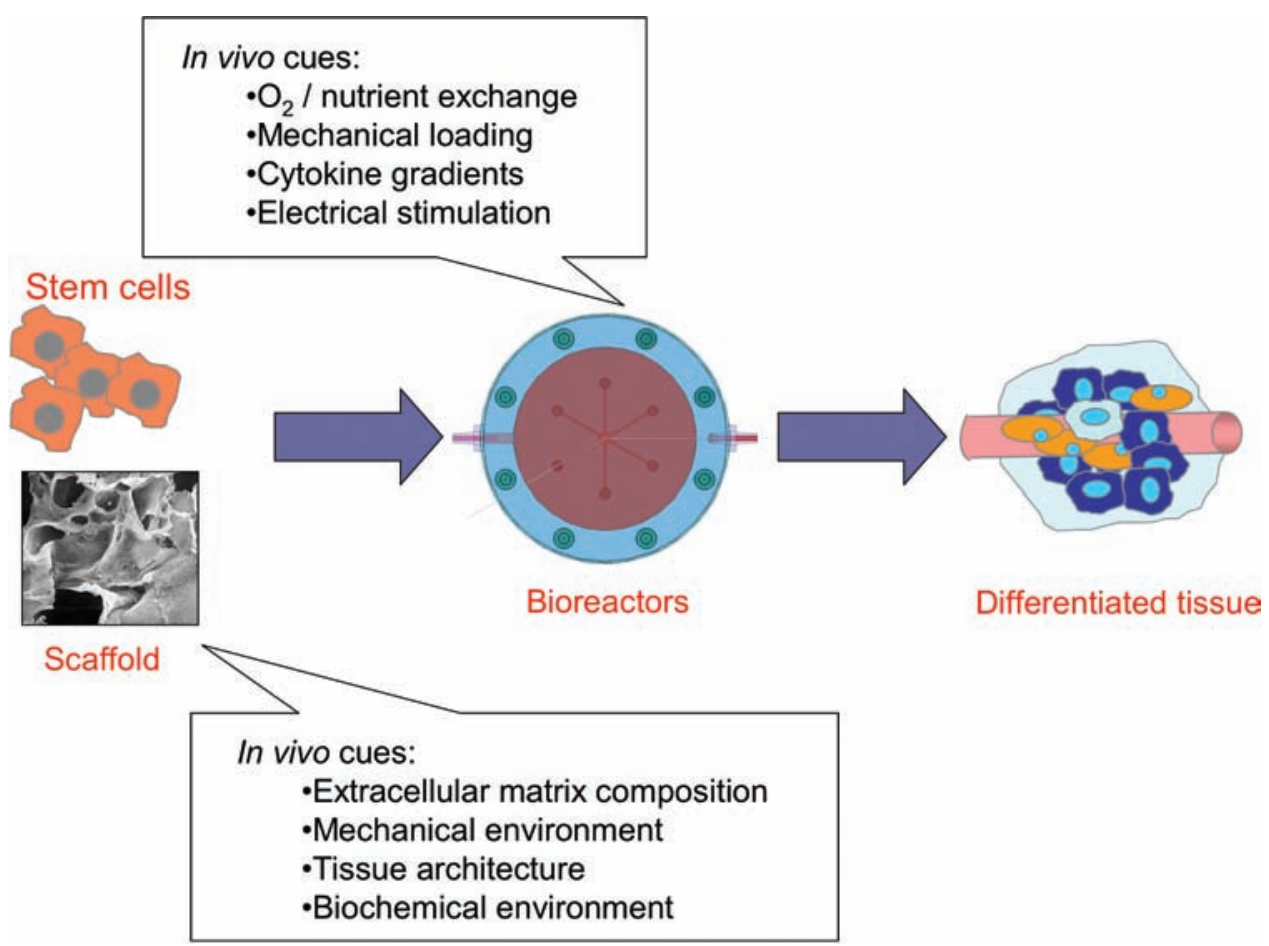




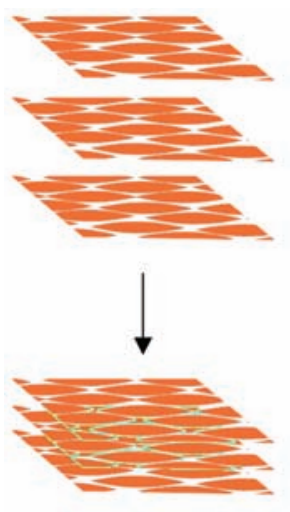

3-D stacks of cell monolayers

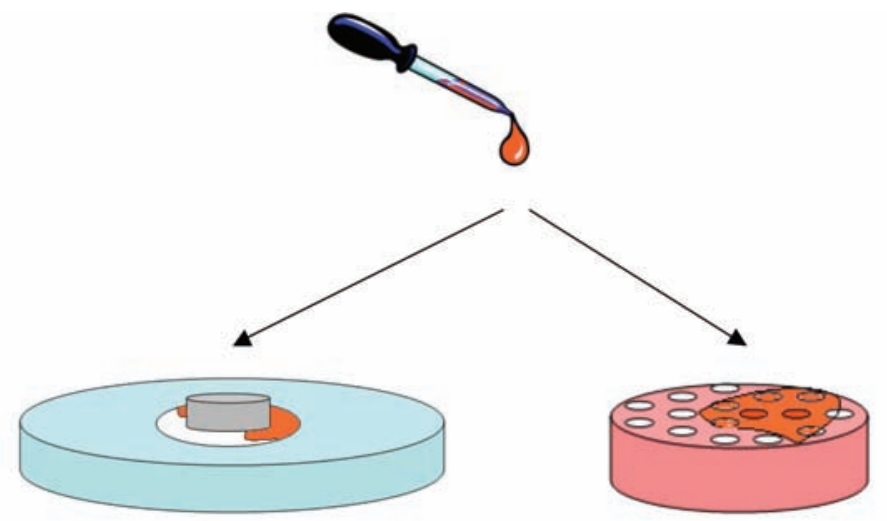

Cells + ECM into mold
Cells + ECM onto

a scaffold

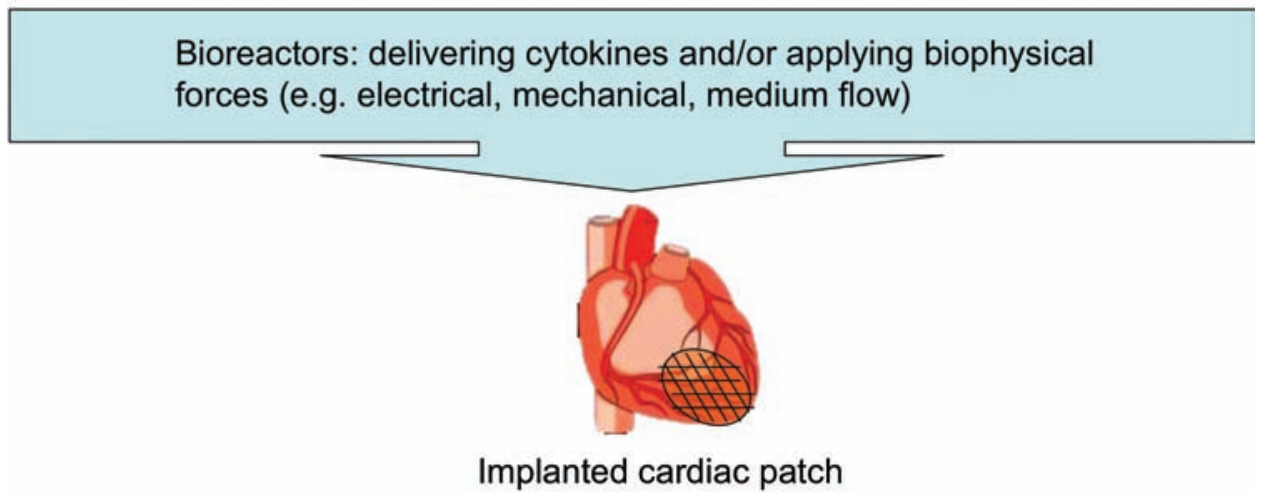

FIG. 4. Current concepts in cardiac tissue engineering. Several approaches have been used to generate 3D cardiac patches in vitro, including the creation of stackable cell sheets without using a scaffold, the use of molds to create constructs of cells cultured in hydrogel, and the culture of cells cultured on porous scaffolds. These constructs may then be subjected to physical stimuli (such as electrical excitation, mechanical stretch, and medium flow) via scaffolds and bioreactors. The major hurdle continues to be finding ways to provide vascularization/blood supply to the cardiac cells. Likely, an approach delivering a combination of relevant factors will need to be used to yield a functional, implantable construct. Color images available online at www.liebertonline.com/ten.

orientation of cardiac myocytes within the ventricular wall is both highly defined and highly anisotropic. The contractile apparatus of cardiac myocytes consists of sarcomeres arranged in parallel. The contractions of the heart are generated by specialized cardiac myocytes-pacemaker cells located in the sinoatrial node. The electrical signals spread from the node over the myocardium, causing depolarization of cell membranes that increases the amount of cytoplasmic calcium, triggering mechanical contraction. The propagation of the electrical excitation through the tissue by ion currents in the extracellular and intercellular spaces orchestrates synchronous contractions that enable pumping of blood.

\section{Establishing the hierarchical scales of cardiac tissue structure}

Tissue engineering has attempted to recapitulate the highly differentiated molecular, structural, and functional properties of the heart at various hierarchical scales in vitro.

At the centimeter scale, tissue engineering aims for compact constructs of a thickness comparable to that of the human myocardium $(\sim 1.5 \mathrm{~cm})$. The main challenge in meeting this requirement is in the high metabolic demand of cardiomyocytes for oxygen $\left(27.6 \mathrm{nmol} / \mathrm{mg}\right.$ [protein.min] $\left.{ }^{111}\right)$ that cannot be met by diffusional supply of oxygen.

At the millimeter scale, the tissue should consist of elongated myofibers aligned in parallel, with cell orientation changing along the thickness of the ventricle. The cells should be capable of synchronous contractions, and the main challenge is in providing appropriate electromechanical stimulation during culture.

At the micrometer scale, the tissue should consist of highcell density myocytes $\left(\sim 108\right.$ cells $\left./ \mathrm{cm}^{3}\right)$ supported by the rich vasculature with capillary distances of $\sim 20 \mu \mathrm{m}$. Vascularization remains a major challenge in cardiac tissue engineering because of the multiple difficult requirements: perfusion within the dense arrays of channels, coculture of cardiac and vascular cells, and immediate connection to the host vasculature after implantation.

At the nanometer scale, cells in the engineered cardiac tissue must be coupled by functional gap junctions and be capable of propagating electrical impulses to prevent arrhythmia upon implantation. The challenge here is to establish functional excitation-contraction machinery of individual cardiomyocytes and to find regimes of electrical or mechanical stimulation (or both) that result in cell coupling. 


\section{Key approaches}

The general tissue engineering paradigm is to combine cells with synthetic or native scaffold materials and then apply different physical and/or chemical conditions to generate tissues that emulate the properties of the native tissues. ${ }^{112,113}$ Taylor and colleagues ${ }^{57}$ took a different and radical approach toward using the entire decellularized rat heart as a scaffold for seeding fresh cells that can recreate the tissue matrix. This process of whole heart decellularization leaves behind the tissue matrix with largely preserved structure, mechanical properties and many of the matrix proteins. The investigators used the nature's own building blocks as a skeleton for building a new organ. The scaffold was seeded by neonatal rat heart cells and cultured for up to 1 month in a bioreactor with coronary perfusion of culture medium, and electrical stimulation was applied to synchronize cell contractions. By day 8 , they observed pumping function that corresponded to about $2 \%$ of adult or $25 \%$ fetal heart function. The next step is to encourage optimal growth at each stage of maturity.

We describe and compare three distinctly different approaches to cardiac tissue engineering that have been most extensively studied: (i) creation of stackable cell sheets without using a scaffold, ${ }^{114}$ (ii) mechanical stimulation of cardiac myocytes cultured in collagen gel, ${ }^{92}$ and (iii) electrical stimulation of cardiac myocytes cultured on porous scaffolds. ${ }^{89}$ Through the analysis of these three approaches, we revisit the challenges of generating synchronously contractile cardiac constructs that can generate force, integrate, vascularize, survive, and function upon implantation.

\section{Tissue engineering by stacking cell sheets}

Shimizu, Okano, and colleagues ${ }^{114}$ proposed a technique that involves stacking of cell sheets to form 3D constructs. Isolated neonatal rat ventricular myocytes would first be cultured on temperature-responsive surfaces. These surfaces are grafted with the temperature-responsive polymer poly $(\mathrm{N}$ isopropylacylamide) by electron beam exposure, yielding surfaces that are slightly hydrophobic and cell adhesive at a cell culture temperature of $37^{\circ} \mathrm{C}$ and can change reversibly to hydrophilic and noncell adhesive below $32^{\circ} \mathrm{C}$. This transient allows cultured cells to detach from the surface without the disruption of cell gap junctions and other surface proteins normally destroyed during enzymatic digestion release by trypsinization. Cell sheets are then layered to form 3D constructs.

After 4 days of culture, confluent cell monolayers were observed to contract simultaneously and spontaneously at about 90 beats $/ \mathrm{min}$. To determine if electrical communication could be established between layered sheets, the investigators layered two sheets on top of one another. Beating initially stopped, but after a week in culture the two sheets began to pulsate spontaneously and simultaneously. Electrical integration of the two sheets was confirmed by recording that the two action potentials occurred simultaneously. The mechanism of this coordination might be similar to the development of the cardiac synctium, in which contractions of uncoupled cells depolarize nearby cells, ${ }^{115}$ leading to the formation of low-resistance coupling junctions at the contact interface. ${ }^{116}$

The utility of the cell-layering technique was further evaluated in an animal model. Cardiomyocyte sheets were implanted subcutaneously in two- and four-sheet layers into
3- and 8-week-old male F344 nude rats, and evaluated for functional performance and histological development. The fractional shortening (measured by change in long-axis length from diastole to systole) was generally greater in the four-layer groups. There was also a significant difference found between implants in the 3- and 8-week-old rats. The investigators suggested that this might be because of an agerelated hormonal difference or mechanical stretch intensity differences. After 3 weeks of implantation, the contractile force for four-layer sheets was $1.18 \pm 0.26 \mathrm{mN}$; the initial or two-layer contractile forces were not reported. It would be interesting to see if subjecting the 2D cell sheets to electrical field stimulation or mechanical stretch, which have been successfully used in engineering 3D cardiac constructs, ${ }^{59,74,89}$ would also benefit the functional cell coupling in 2D sheets.

Limitations of thickness and vascularization: The celllayering technique addresses the diffusion limitations of construct growth by gradually and incrementally increasing the construct thickness. In the implant model, multiple sites of neovascularization were seen originating from subcutaneous tissue into the layered grafts. Previous studies ${ }^{117}$ showed that a single layer of endothelial cells enhances the formation of capillaries in vivo. Therefore, inserting endothelial cell sheets between the cardiomyocyte cell sheets could further promote the formation of a vascular network in the constructs. In recent studies, it was shown that myocardial cell sheets can be layered into electrically communicative cardiac constructs and transplanted onto the damaged hearts in animal models to improve heart function. ${ }^{118}$ The thickness of cells sheets that can be achieved by this approach is limited to $\sim 80 \mu \mathrm{m}$, and this limitation can be overcome by multiple transplantation of cell sheets, to enable vascularization between the two successive transplantation steps. ${ }^{84}$ Although this approach serves as an excellent model for studies of vascularization, it might be impractical for human application. The main challenge will be to overcome the limitation in construct thickness by developing an effective method for vascularization. Clearly, vascularization remains a major challenge of cardiac tissue engineering, and tissue engineering in general.

\section{Tissue engineering with the application of mechanical stretch}

Eschenhagen and Zimmermann established an effective approach to cardiac tissue engineering by cultivation of neonatal rat heart cells in collagen gel and Matrigel ${ }^{\circledR}$, with the application of mechanical stretch. ${ }^{59,92,119,120}$ Under these conditions, cells formed highly differentiated cardiac muscle synctium that exhibited contractile and electrophysiological properties of working myocardium. Implantation experiments in healthy rats showed survival and vascularization of the tissue grafts. ${ }^{92}$ Implantation experiments in infarcted rats demonstrated, rigorously and convincingly, that these constructs, when placed over the infarct bed, delay the thinning of the heart wall and induce functional improvement. ${ }^{74}$

In the first version of this approach, neonatal rat ventricular myocytes were suspended in a gel consisting of collagen I and Matrigel that was casted in wells and allowed to gel. ${ }^{119}$ After 4 days in culture, the cell-gel strips were transferred to a motorized stretching device and subjected to unidirectional or cyclic stretch for 6 days. These early studies showed that 
the stretch improved organization of cardiac myocytes, increased the mitochondrial density, the length of myofilaments, and the force of contraction. ${ }^{119}$ In an improved set-up, neonatal rat cardiac cells were suspended in the collagen/ Matrigel mix and cast into circular molds. ${ }^{74}$ After 7 days in culture, the strips of cardiac tissue were placed around two rods of a mechanical stretcher and subjected to unidirectional and cyclic stretch at $10 \%$ strain and $2 \mathrm{~Hz}$.

Structural organization: The level of structural and functional organization of the dissociated cells in hydrogel that was achieved within a relatively short time period was quite remarkable. Cells reconstituted cardiac-like tissue with interconnected, oriented cells displaying sarcomeres, adherens junctions, gap junctions, and desmosomes. Ultrastructurally, cardiac myocytes displayed a predominant orientation of sarcomeres along the longitudinal axis of the cell and were composed of $\mathrm{Z}, \mathrm{I}, \mathrm{A}$, and $\mathrm{H}$ bands, with occasional presence of $\mathrm{M}$ bands. Importantly, capillary structures positive for CD31 were also noted. Functionally, the constructs exhibited contractile properties similar to those in native tissue, with a high ratio of twitch to resting tension, strong $\beta$-adrenegenic response, and action potentials characteristic of rat ventricular myocytes.

Although cells in cardiac constructs were more elongated than those from immature tissue and displayed some cross striation, it is important to note that cardiac myocytes in the construct were smaller than those in the adult tissue, and the construct was less compact than the adult tissue. In addition, muscle bundles were small—ranging from 30 to $100 \mu \mathrm{m}$, corresponding to the oxygen penetrating depth for avascular tissue, and the outer surface consisted of nonmyocytes, fibroblasts (which did not overgrow the cardiomyocytes but instead appeared to shield the cardiomyocytes from stress), smooth muscle cells, endothelial cells, and macrophages. In terms of functionality, despite the high ratio of twitch to resting tension, the contractile force was still less than onetenth that of the native tissue.

Functional improvement: The size, homogeneity, and relative strength of the engineered tissues were further improved in a recent study by the same group. ${ }^{74}$ The loop-shaped constructs created by mixing isolated neonatal rat cells with collagen type I, Matrigel, and growth supplements and allowing to harden in circular molds were subjected to mechanical strain to facilitate the development of contractile and electrophysiological properties of working myocardium. ${ }^{92}$ To increase the construct size, five loop-shaped constructs were fused to form a single synchronously contracting multiloop construct with a diameter of about $15 \mathrm{~mm}$ and a thickness of $1-4 \mathrm{~mm}$. These constructs were investigated for ability to support contractile function of infarcted hearts in an immunosupressed rat model.

Four weeks after implantation, the grafts could still be identified by their distinct appearance. Myocytes labeled with 4',6-diamidino-2-phenylindole (DAPI) before implantation were found only in the grafts, and there was no migration of cardiac cells between the native tissue and the constructs. Pacing of the implanted constructs resulted in propagated electrical responses in remote myocardium, whereas pacing through noncontractile grafts made of formaldehyde-fixed constructs did not provoke any propagated potentials. In addition, implanted cardiac constructs and native tissue appeared to exhibit similar conduction velocity and anisotropy.
The combination of conduction velocity characteristics and electrical coupling led to undelayed epicardial activation around the implant site in grafted hearts, as compared with the sham hearts (that were infarcted but received no implant) that showed a $20-30 \mathrm{~ms}$ activation delay around the infarct.

As compared with controls (untreated infarctions, shamoperated rats, noncontractile constructs), engineered constructs prevented further dilation of the ventricle wall and improved fractional area shortening of infarcted hearts. Implanted constructs had a high connective tissue content and contained $\sim 400 \mu \mathrm{m}$ thick strands of compact and welldifferentiated cardiac-like muscles (as compared with 30$100 \mu \mathrm{m}$ thick strands observed in previous studies). Since diffusion alone would only be capable of supplying a $\leq 100 \mu \mathrm{m}$ thick construct, some vascular network must have formed to deliver blood to the tissue, consistent with their previous observation of the formation of primitive capillaries in constructs in vitro. ${ }^{92}$ Blood vessels found in the implanted constructs formed only from the donor $\left(\mathrm{DAPI}^{+}\right)$cells, suggesting that the contact between the host and implant vessels leads to integration of the two systems and to perfusion of the implanted engineered cardiac construct. This finding is important because of the possibility that further development of the primitive capillaries in engineered constructs in vitro may yield greater perfusion of the constructs in vivo, thus allowing for a thicker cardiac tissue implant.

Functionally, the hearts showed significant enlargement of left ventricular dimension and volume 14 days after infarction. Twenty-eight days later, sham hearts had a greatly increased left ventricular end diastolic volume and pressure, whereas implanted hearts showed only a small increase in each of these parameters. Representative pressure-volume loops revealed that the end systolic pressure-volume relation had a significantly higher slope in the cardiac construct grafted group than in the sham control. Thus, grafted hearts were able to develop a greater active force than those not grafted. This is indicative of the engineered constructs playing a significant role in the contractile activity of the infarcted hearts. Although the implants did not reverse the problems associated with infarction, they did significantly improve the diastolic and systolic function of the heart.

The approach developed by Eschenhagen and colleagues ${ }^{91}$ has shown, in a rigorous and convincing way, that immature cardiac cell populations have remarkable ability to assemble into cardiac constructs, if subjected to mechanical signals during cultivation. They also showed that the loopshaped constructs, assembled into larger structures, can not only slow down the progression of heart disease in an animal model of chronic infarction but also result in functional improvements. We follow with great interest the ongoing efforts of this group to extend their technology to human cell sources.

\section{Tissue engineering with medium perfusion and electrical stimulation}

Our laboratory has developed a biomimetic approach to cardiac tissue engineering of compact, millimeters thick, synchronously contracting cardiac tissue constructs, by providing: (i) convective-diffusive oxygen transport (critical for cell survival and function) and (2) excitation-contraction coupling (critical for cell differentiation and assembly). 
To mimic the capillary network, culture medium was perfused through a channeled scaffold seeded with cells at a physiologic density; to mimic oxygen supply by hemoglobin, the culture medium is supplemented with an oxygen carrier. $^{78,121}$ To promote cell differentiation and functional assembly, cultured constructs were subjected to electrical signals designed to mimic those in native heart, to induce synchronous construct contractions. ${ }^{89}$ Perfusion of culture medium containing an oxygen carrier, perfluorocarbon (PFC), enabled the maintenance of physiologic density of viable, differentiated cells in millimeters thick constructs. Electrical field stimulation induced cell alignment and coupling, increased the amplitude of synchronous contractions, and resulted in a remarkable level of ultrastructural organization of engineered myocardium, over only 8 days of cultivation.

Convective-diffusive oxygen supply by medium perfusion: To provide oxygen supply to the cells, we developed a technique that involves (i) rapid cell inoculation into collagen sponges using Matrigel as a cell delivery vehicle and (ii) transfer of inoculated scaffolds into perfused cartridges with immediate establishment of the interstitial flow of culture medium. Forward-reverse flow was used for the initial period of $1.5-4.5 \mathrm{~h}$ to further increase the spatial uniformity of cell seeding. ${ }^{75}$ In this system, cells were "locked" into the scaffold during a short $(10 \mathrm{~min})$ gelation period and supplied with oxygen at all times during culture. Medium perfusion during seeding was critical for engineering thick constructs with high and spatially uniform densities of viable cells.

Notably, the final cell viability in perfused constructs cultured for 8 days was indistinguishable from the viability of the freshly isolated cells and markedly higher than the cell viability in dish-grown constructs. ${ }^{89}$ Perfused constructs and native ventricles had more cells in the $S$ phase than in the G2/M phases, whereas the cells from dish-grown constructs appeared unable to complete the cell cycle and accumulated in the $\mathrm{G} 2 / \mathrm{M}$ phase. Cells expressing cardiac markers (sarcomeric $\alpha$-actin, sarcomeric tropomyosin, cardiac troponin I) were present throughout the perfused constructs. In response to electrical stimulation, perfused constructs contracted synchronously had lower excitation thresholds and recovered their baseline function levels after treatment with a gap junction blocker.

However, most cells in perfused constructs were round and mononucleated, a situation that was likely because of the exposure of cardiac myocytes to hydrodynamic shear, in contrast to the native heart muscle where blood is confined within the capillary bed and is not in direct contact with cardiac myocytes. This motivated the design of scaffolds with arrays of channels that provide a separate compartment for medium flow. Porous elastomer scaffolds made of poly(glycerol sebacate) ${ }^{122}$ were fabricated with an array of channels and pretreated with neonatal rat fibroblasts, followed by addition of rat cardiomyocytes and perfusion culture. ${ }^{99}$ After only 3 days, constructs contracted synchronously in response to electrical stimulation, while channels remained open, and the pressure drop was as low as $0.1 \mathrm{kPa} / \mathrm{mm}$.

Oxygen transport from the PFC particles further increased oxygen concentrations in the medium. ${ }^{99,121}$ At the best conditions tested, the minimum oxygen concentration was $33 \mu \mathrm{M}$, that is, approximately five times above the $\mathrm{Km} 91$. Constructs cultivated in the presence of PFC had higher amounts of DNA, troponin I, and Cx-43, and significantly better con- tractile properties as compared with the static controls. Improved construct properties were correlated with the enhanced supply of oxygen to the cells, using a mathematical model of oxygen distribution in channeled cardiac constructs that were used to evaluate the effects of perfusion, oxygen carrier, and scaffold geometry on viable cell density. ${ }^{123}$

Excitation-contraction coupling by electrical stimulation: In native heart, mechanical stretch is induced by electrical signals, and the orderly coupling between electrical pacing signals and macroscopic contractions is crucial for the development and function of native myocardium. ${ }^{4}$ Electrical signals designed to induce construct contractions during cultivation were investigated for their ability to enhance cell differentiation and functional assembly of engineered tissue via physiologically relevant mechanisms. ${ }^{16,89}$ Cardiac constructs prepared by seeding neonatal rat cardiomyocytes in Matrigel onto collagen sponges were cultured for 3 days before being subjected to trains of electrical pulses $(5 \mathrm{~V} / \mathrm{cm}$, $1 \mathrm{~Hz}, 2 \mathrm{~ms}$ duration).

Electrical stimulation resulted in the progressive development of conductive and contractile properties. On a molecular level, electrical stimulation increased the expression of myosin heavy chain, Cx-43, creatine kinase-MM, and cardiac troponin-I. Morphologically, cells in stimulated constructs were more aligned and elongated, and contained abundant mitochondria, in addition to cells with clearly visible $\mathrm{M}$ and $\mathrm{Z}$ lines and $\mathrm{H}, \mathrm{I}$, and $\mathrm{A}$ bands closely resembling those in native myocardium. The effects of electrical stimulation depended strongly on the time of its initiation, indicating that cells required some time to reassemble their excitation-contraction coupling machinery before electrical stimulation could provide any reinforcement of its positive effects on cellular differentiation.

The shape, amplitude, and duration of the electrical activity recorded in an electrically stimulated construct were qualitatively similar to those obtained in Eschenhagen group's study: we both reported a fast upstroke time and an approximately $200 \mathrm{~ms}$ plateau phase. The fundamental questions about the relative benefits achieved from the application of mechanical stretch and electrical stimulation remain to be addressed in more detail.

In beating tissue, through excitation-contraction coupling, electrical stimulation causes cell contractions and phasic stretch, but phasic stretch may also cause electrical stimulation through the deformation of cells and subsequent redistribution of charge. Fibroblasts can also respond to mechanical deformation with characteristic changes of their membrane potential. They depolarize during contraction because of an influx of cations (mainly sodium); conversely, during diastolic relaxation, they hyperpolarize because of reduced sodium entry and increased potassium egress. ${ }^{124,125}$ Because of the high degree of electromechanical coupling, it will be interesting to decipher the separate roles of mechanical and electrical stimulation of engineering cardiac constructs.

\section{Electrical versus mechanical stimulation}

In constructs cultured with verapamil, electrical stimulation maintained the amount of $\mathrm{Cx}-43$ at levels comparable with stimulated drug-free controls, suggesting that electrical stimulation, even without contractile activity, aids to the establishment of functional gap junctions. ${ }^{89}$ Similarly, 


\section{Table 1. Key Challenges}

- Cells are the actual "tissue engineers," we only engineer the environments that can predictably mediate their differentiation and developmental processes.

- Design requirements for tissue engineering systems should be "biomimetic," which is based on the information obtained from developmental and adult biology.

- A range of cell types-adult, embryonic, induced and resident stem cells - is under consideration as sources of cardiac and vascular cells for heart regeneration.

- Vascularization is essential for the implementation of cardiac grafts.

- Functional integration between the graft and host tissuesboth electromechanical and vascular-remains a major challenge.

- The establishment of cardiac tissue function is most difficult to achieve and rigorously evaluate.

- The question "How much is enough?" in terms of construct function, for implantation and in vitro studies, remains to be answered.

- Advanced technologies for three-dimensional culture are critical for establishing correspondence between in vitro and in vivo studies.

- Functional imaging will greatly facilitate bringing regenerative medicine to the next level of understanding.

mechanical stimulation resulted in functional coupling of cardiac cells. ${ }^{74}$ It is difficult to directly compare the two methods because of the different methods used to assess functional performance: force of contraction versus the electrical excitability. Phasic stretch and electrical stimulation each appeared to greatly enhance the differentiation of cardiomyocytes, and it may be speculated that a method incorporating the application of both factors could outperform a regime applying just one.

In addition to cyclic mechanical stimulation, medium perfusion, and electrical stimulation, there may be other biophysical cues of importance, including static stretch and topographical cues. Passive stretching of cardiac myocytes and fibroblasts induced specific gene expression as well as cell hypertrophy. ${ }^{126,127}$ Since cardiac myocytes cannot divide later in life, they respond to the demand for increased mass by an increase in cell size (hypertrophy). ${ }^{128}$ In another study, progressive, unidirectional lengthening increased cardiomyocyte elongation, binucleation, and hypertrophy by longitudinal cell growth. ${ }^{129}$ In terms of topographical cues, in coculture of cardiac fibroblasts and myocytes, the two cell types aligned in the same direction..$^{90,130}$ The historic emphasis on the myocyte has relegated the role of cardiac fibroblasts to synthesis and remodeling of the heart's ECM, ${ }^{131}$ but recent work documents that fibroblasts have much broader functions in the myocardium, including electrical coupling with cardiomyocytes, and propagation of electrical stimuli over $100 \mu \mathrm{m}$ distances. ${ }^{124,125,131}$

\section{Conclusion}

The regenerative capacity of adult human myocardium is minimal and grossly insufficient to compensate for the loss of cardiac myocytes and supporting vasculature after myocardial infarction. To drive regeneration, the right types of cells need to be delivered into the right location. Understanding of factors present during and after the injury is critical for the development of efficacious cell-based therapies, ${ }^{93}$ as is the application of technologies for cell characterization, cultivation, delivery, and monitoring. ${ }^{113}$

There is no tissue repair without the cell, either recruited from the host or supplied from an external source. One dominant approach is to apply the cells, matrix, molecular, and physical regulatory factors that play roles during normal development for inducing tissue development and remodeling. Concepts that are intrinsic for developmental (and adult) biology are thus becoming essential for the new generation of tissue engineering technologies: temporal and spatial signaling, niche development, and an integrated use of regulatory factors. Interestingly, in many cases, the best strategy for engineering functional tissue grafts is a simple one-not everything needs to be recapitulated, and one key factor provided within the right context can make the difference. The application of mechanical or electrical stimulation to high-density cultures of cells on scaffolds is an excellent example of this situation.

Some of the current challenges of cardiac tissue engineering are summarized in Table 1. In spite of the enormous biologic complexity of the heart, success has been achieved with engineering cardiac-like pieces of tissue, using several different approaches. It is becoming increasingly possible that engineered cardiac tissue will be in use in the near future. Given the complexity of regulatory issues, and the existing uncertainties about the selection of an autologous yet biologically suitable human cell source, it is likely that the first applications of engineered cardiac tissue will be those in vitro-in experimental models of development and disease-and only later in clinical use for cardiac regeneration.

\section{Acknowledgments}

This work is supported by NIH (R01 HL076485, R21 HL089913, P41-EB002520 to G.V.-N.), NSERC, and CFI LOF grants (to M.R.), NIH Graduate Fellowship (to R.M., from T 32 HL087745), and Presidential Fellowship of Columbia University (to N.T.).

\section{Disclosure Statement}

No competing financial interests exist.

\section{References}

1. Harrison, R.G. Observations on the living developing nerve fiber. Proc Soc Exp Biol Med 4, 140, 1907.

2. Langer, R., and Vacanti, J.P. Tissue Eng Sci 260, 920, 1993.

3. Lanza, R., Langer, R., and Vacanti, J. Principles of Tissue Engineering, Boston: Elsevier Academic Press, 2007.

4. Severs, N.J. The cardiac muscle cell. Bioessays 22, 188, 2000.

5. American Heart Association Cardiovascular Disease Statistics. 2008.

6. Passier, R., van Laake, L.W., and Mummery, C.L. Stem-cellbased therapy and lessons from the heart. Nature 453, 322, 2008.

7. Laugwitz, K.-L., Moretti, A., Caron, L., Nakano, A., and Chien, K.R. Islet1 cardiovascular progenitors: a single source for heart lineages? Development 135, 193, 2008.

8. Orlic, D., Kajstura, J., Chimenti, S., Jakoniuk, I., Anderson, S.M., Li, B., et al. Bone marrow cells regenerate infarcted myocardium. Nature 410, 701, 2001. 
9. Yang, L., Soonpaa, M.H., Adler, E.D., Roepke, T.K., Kattman, S.J., Kennedy, M., et al. Human cardiovascular progenitor cells develop from a KDR + embryonic-stem-cellderived population. Nature 453, 524, 2008.

10. Gimble, J.M., Katz, A.J., and Bunnell, B.A. Adipose-derived stem cells for regenerative medicine. Circ Res 100, 1249, 2007.

11. Anker, P.S., Scherjon, S.A., Kleijburg-van der Keur, C., Noort, W.A., Claas, F.H.J., Willemze, R., Fibbe, W.E., and Kanhai, H.H.H. Amniotic fluid as a novel source of mesenchymal stem cells for therapeutic transplantation. Blood 102, 1548, 2003

12. Pei, M., He, F., and Vunjak-Novakovic, G. Synoviumderived stem cell-based chondrogenesis. Differentiation 76, 1044, 2008.

13. Miura, M., Gronthos, S., Zhao, M., Lu, B., Fisher, L.W., Robey, P.G., et al. SHED: stem cells from human exfoliated deciduous teeth. Proc Natl Acad Sci USA 100, 5807, 2003.

14. Zhang, S., Wang, D., Estrov, Z., Raj, S., Willerson, J.T., and Yeh, E.T.H. Both cell fusion and transdifferentiation account for the transformation of human peripheral blood CD34-positive cells into cardiomyocytes in vivo. Circulation 110, 3803, 2004.

15. Caspi, O., Lesman, A., Basevitch, Y., Gepstein, A., Arbel, G., Habib, I.H.M., et al. Tissue engineering of vascularized cardiac muscle from human embryonic stem cells. Circ Res 100, 263, 2007.

16. Burdick, J.A., and Vunjak-Novakovic, G. Engineered microenvironments for controlled stem cell differentiation. Tissue Eng Part A 15, 205, 2009.

17. Hunt, J.A. Regenerative medicine: materials in a cellular world. Nat Mater 7, 617, 2008.

18. Asahara, T., Murohara, T., Sullivan, A., Silver, M., van der Zee, R., Li, T., et al. Isolation of putative progenitor endothelial cells for angiogenesis. Science 275, 964, 1997.

19. Takahashi, T., Kalka, C., Masuda, H., Chen, D., Silver, M., Kearney, M., et al. Ischemia- and cytokine-induced mobilization of bone marrow-derived endothelial progenitor cells for neovascularization. Nat Med 5, 434, 1999.

20. Kocher, A.A., Schuster, M.D., Szabolcs, M.J., Takuma, S., Burkhoff, D., Wang, J., et al. Neovascularization of ischemic myocardium by human bone-marrow-derived angioblasts prevents cadiomyocyte apoptosis, reduces remodeling and improves cardiac function. Nat Med 7, 430, 2001.

21. Taichman, R.S. Blood and bone: two tissues whose fates are intertwined to create the hematopoietic stem-cell niche. Blood 105, 2631, 2005.

22. Berardi, A.C., Wang, A., Levine, J.D., Lopez, P., and Scadden, D.T. Functional isolation and characterization of human hematopoietic stem cells. Science 267, 104, 1995.

23. Martin-Henao, G.A., Picon, M., Amill, B., Querol, S., Gonzalez, J.R., Martinez, C., et al. Isolation of CD34+ progenitor cells from peripheral blood by use of an automated immunomagnetic selection system: factors affecting the results. Transfusion 40, 35, 2000.

24. Shmelkov, S.V., St. Clair, R., Lyden, D., and Rafii, S. AC133/CD133/prominin-1. Int J Biochem Cell Biol 37, 715, 2005.

25. Balsam, L.B., Wagers, A.J., Christensen, J.L., Kofidis, T., Weissman, I.L., and Robbins, R.C. Haematopoietic stem cells adopt mature haematopoietic fates in ischaemic myocardium. Nature 428, 668, 2004.

26. Pittenger, M.F., and Martin, B.J. Mesenchymal stem cells and their potential as cardiac therapeutics. Circ Res 95, 9, 2004.
27. Makino, S., Fukuda, K., Miyoshi, S., Konishi, F., Kodama, H., Pan, J., et al. Cardiomyocytes can be generated from marrow stromal cells in vitro. J Clin Investig 103, 697, 1999.

28. Aggarwal, S., and Pittenger, M.F. Human mesenchymal stem cells modulate allogeneic immune cell responses. Blood 105, 1815, 2005.

29. Amado, L.C., Saliaris, A.P., Schuleri, K.H., St. John, M., Xie, J.-S., Cattaneo, S., et al. Cardiac repair with intramyocardial injection of allogeneic mesenchymal stem cells after myocardial infarction. Proc Natl Acad Sci USA 102, 11474, 2005.

30. Silva, G.V., Litovsky, S., Assad, J.A.R., Sousa, A.L.S., Martin, B.J., Vela, D., et al. Mesenchymal stem cells differentiate into an endothelial phenotype, enhance vascular density, and improve heart function in a canine chronic ischemia model. Circulation 111, 150, 2005.

31. Martens, T.P., See, F., Schuster, M.D., Sondermeijer, H.P., Hefti, M.M., Zannettino, A., et al. Mesenchymal lineage precursor cells induce vascular network formation in ischemic myocardium. Nat Clin Pract Cardiovasc Med 1, S18, 2006.

32. Mangi, A.A., Noiseux, N., Kong, D., He, H., Rezvani, M., Ingwall, J.S., et al. Mesenchymal stem cells modified with Akt prevent remodeling and restore performance of infarcted hearts. Nat Med 9, 1195, 2003.

33. Schulze, M., Belema-Bedada, F., Technau, A., and Braun, T. Mesenchymal stem cells are recruited to striated muscle by NFAT/IL-4-mediated cell fusion. Genes Dev 19, 1787, 2005.

34. Assmus, B., Honold, J., Schachinger, V., Britten, M.B., Fischer-Rasokat, U., Lehmann, R., et al. Transcoronary transplantation of progenitor cells after myocardial infarction. N Engl J Med 355, 1222, 2006.

35. Janssens, Dubois, C., Bogaert, J., Theunissen, K., Deroose, C., Desmet, W., Kalantzi, M., Herbots, L., Sinnaeve, P., Dens, J., Maertens, J., Rademakers, F., Dymarkowski, S., Gheysens, O., Van Cleemput, J., Bormans, G., Nuyts, J., Belmans, A., Mortelmans, L., Boogaerts, M., and Van de Werf, F. Autologous bone marrow-derived stem-cell transfer in patients with ST-segment elevation myocardial infarction: double-blind, randomised controlled trial. Lancet 367, 113, 2006.

36. Lunde, K., Solheim, S., Aakhus, S., Arnesen, H., Abdelnoor, M., Egeland, T., et al. Intracoronary injection of mononuclear bone marrow cells in acute myocardial infarction. N Engl J Med 355, 1199, 2006.

37. Schachinger, V., Erbs, S., Elsasser, A., Haberbosch, W., Hambrecht, R., Holschermann, H., et al. Intracoronary bone marrow-derived progenitor cells in acute myocardial infarction. N Engl J Med 355, 1210, 2006.

38. Schächinger, V., Tonn, T., Dimmeler, S., and Zeiher, A.M. Bone-marrow-derived progenitor cell therapy in need of proof of concept: design of the REPAIR-AMI trial. Nat Clin Pract Cardiovasc Med 3, S23, 2006.

39. Planat-Benard, V., Menard, C., Andre, M., Puceat, M., Perez, A., Garcia-Verdugo, J.M., et al. Spontaneous cardiomyocyte differentiation from adipose tissue stroma cells. Circ Res 94, 223, 2004.

40. Menasche, P. Skeletal myoblast for cell therapy. Coron Artery Dis 16, 105, 2005.

41. Léobon, B., Garcin, I., Menasché, P., Vilquin, J.-T., Audinat, E., and Charpak, S. Myoblasts transplanted into rat infarcted myocardium are functionally isolated from their host. Proc Natl Acad Sci USA 100, 7808, 2003.

42. Dib, N., Michler, R.E., Pagani, F.D., Wright, S., Kereiakes, D.J., Lengerich, R., et al. Safety and feasibility of autologous 
myoblast transplantation in patients with ischemic cardiomyopathy: four-year follow-up. Circulation 112, 1748, 2005.

43. Roell, W., Lewalter, T., Sasse, P., Tallini, Y.N., Choi, B.-R., Breitbach, M., et al. Engraftment of connexin 43-expressing cells prevents post-infarct arrhythmia. Nature 450, 819, 2007.

44. Murry, C.E. Cardiac aid to the injured but not the elderly? Nat Med 13, 901, 2007.

45. Laflamme, M.A., and Murry, C.E. Regenerating the heart. Nat Biotechol 23, 845, 2005.

46. van Laake, L.W., Passier, R., Doevendans, P.A., and Mummery, C.L. Human embryonic stem cell-derived cardiomyocytes and cardiac repair in rodents. Circ Res 102, $1008,2008$.

47. Nussbaum, J., Minami, E., Laflamme, M.A., Virag, J.A.I., Ware, C.B., Masino, A., et al. Transplantation of undifferentiated murine embryonic stem cells in the heart: teratoma formation and immune response. FASEB J 21, 1345, 2007.

48. Nakagawa, M., Koyanagi, M., Tanabe, K., Takahashi, K., Ichisaka, T., Aoi, T., et al. Generation of induced pluripotent stem cells without Myc from mouse and human fibroblasts. Nat Biotechnol 26, 101, 2008.

49. Narazaki, G., Uosaki, H., Teranishi, M., Okita, K., Kim, B., Matsuoka, S., et al. Directed and systematic differentiation of cardiovascular cells from mouse induced pluripotent stem cells. Circulation 118, 498, 2008.

50. Park, I.H., Arora, N., Huo, H., Maherali, N., Ahfeldt, T., Shimamura, A., et al. Disease-specific induced pluripotent stem cells. Cell 134, 877, 2008.

51. Gonzalez, F., Barragan Monasterio, M., Tiscornia, G., Montserrat Pulido, N., Vassena, R., Batlle Morera, L., et al. Generation of mouse-induced pluripotent stem cells by transient expression of a single nonviral polycistronic vector. Proc Natl Acad Sci USA 106, 8918, 2009.

52. Laugwitz, K.-L., Moretti, A., Lam, J., Gruber, P., Chen, Y., Woodard, S., Lin, L.-Z., Cai, C.-L., Lu, M.M., Reth, M., Platoshyn, O., Yuan, J.X.J., Evans, S., and Chien, K.R. Postnatal isl1+ cardioblasts enter fully differentiated cardiomyocyte lineages. Nature 433, 647, 2005.

53. Smith, R.R., Barile, L., Cho, H.C., Leppo, M.K., Hare, J.M., Messina, E., Giacomello, A., Abraham, M.R., and Marban, E. Regenerative potential of cardiosphere-derived cells expanded from percutaneous endomyocardial biopsy specimens. Circulation 115, 896, 2007.

54. Evans, S.M., Mummery, C., and Doevendans, P.A. Progenitor cells for cardiac repair. Semin Cell Dev Biol 18, 153, 2007.

55. Laflamme, M.A., Chen, K.Y., Naumova, A.V., Muskheli, V., Fugate, J.A., Dupras, S.K., et al. Cardiomyocytes derived from human embryonic stem cells in pro-survival factors enhance function of infarcted rat hearts. Nat Biotechnol 25, 1015, 2007.

56. Menasché, P. The potential of embryonic stem cells to treat heart disease. Curr Opin Mol Ther 7, 293, 2005.

57. Ott, H.C., Matthiesen, T.S., Goh, S.-K., Black, L.D., Kren, S.M., Netoff, T.I., and Taylor, D.A. Perfusion-decellularized matrix: using nature's platform to engineer a bioartificial heart. Nat Med 14, 213, 2008.

58. Radisic, M., Marsano, A., Maidhof, R., Wang, Y., and Vunjak-Novakovic, G. Cardiac tissue engineering using perfusion bioreactor systems. Nat Protoc 3, 719, 2008.

59. Eschenhagen, T., Fink, C., Remmers, U., Scholz, H., Wattchow, J., Weil, J., et al. Three-dimensional reconstitution of embryonic cardiomyocytes in a collagen matrix: a new heart muscle model system. FASEB J 11, 683, 1997.
60. Dawson, E., Mapili, G., Erickson, K., Taqvi, S., and Roy, K. Biomaterials for stem cell differentiation. Adv Drug Deliv Rev 60, 215, 2008.

61. Nair, L.S., and Laurencin, C.T. Biodegradable polymers as biomaterials. Prog Polym Sci 32, 762, 2007.

62. Nerurkar, N.L., Elliott, D.M., and Mauck, R.L. Mechanics of oriented electrospun nanofibrous scaffolds for annulus fibrosus tissue engineering. J Orthop Res 25, 1018, 2007.

63. Engler, A.J., Sen, S., Sweeney, H.L., and Discher, D.E. Matrix elasticity directs stem cell lineage specification. Cell 126, 677, 2006.

64. Hwang, N.S., Varghese, S., and Elisseeff, J. Controlled differentiation of stem cells. Adv Drug Deliv Rev 60, 199, 2008.

65. Ferreira, L.S., Gerecht, S., Fuller, J., Shieh, H.F., VunjakNovakovic, G., and Langer, R. Bioactive hydrogel scaffolds for controllable vascular differentiation of human embryonic stem cells. Biomaterials 28, 2706, 2007.

66. Siminiak, T., Burchardt, P., and Kurpisz, M. Postinfarction heart failure: surgical and trans-coronary-venous transplantation of autologous myoblasts. Nat Clin Pract Cardiovasc Med 3 Suppl 1, S46, 2006.

67. Sherman, W., and Martens, T.P. Catheter-based delivery of cells to the heart. Nat Clin Pract Cardiovasc Med 3, S57, 2006.

68. Radisic, M., Yang, L., Boublik, J., Cohen, R.J., Langer, R., Freed, L.E., et al. Medium perfusion enables engineering of compact and contractile cardiac tissue. Am J Physiol Heart Circ Physiol 286, H507, 2004.

69. Bursac, N., Papadaki, M., Cohen, R.J., Schoen, F.J., Eisenberg, S.R., Carrier, R., et al. Cardiac muscle tissue engineering: toward an in vitro model for electrophysiological studies. Am J Physiol Heart Circ Physiol 277, H433, 1999.

70. Carrier, R.L., Papadaki, M., Rupnick, M., Schoen, F.J., Bursac, N., Langer, R., et al. Cardiac tissue engineering: cell seeding, cultivation parameters and tissue construct characterization. Biotechnol Bioeng 64, 580, 1999.

71. Kofidis, T., Lenz, A., Boublik, J., Akhyari, P., Wachsmann, B., Mueller-Stahl, K., et al. Pulsatile perfusion and cardiomyocyte viability in a solid three-dimensional matrix. Biomaterials 24, 5009, 2003.

72. Dvir, T., Benishti, N., Shachar, M., and Cohen, S. A novel perfusion bioreactor providing a homogenous milieu for tissue regeneration. Tissue Eng 12, 2843, 2006.

73. Dvir, T., Levy, O., Shachar, M., Granot, Y., and Cohen, S. Activation of the ERK1/2 cascade via pulsatile interstitial fluid flow promotes cardiac tissue assembly. Tissue Eng 13, 2185, 2007.

74. Zimmermann, W.-H., Melnychenko, I., Wasmeier, G., Didie, M., Naito, H., Nixdorff, U., Hess, A., Budinsky, L., Brune, K., Michaelis, B., Dhein, S., Schwoerer, A., Ehmke, $\mathrm{H}$. , and Eschenhagen, T. Engineered heart tissue grafts improve systolic and diastolic function in infarcted rat hearts. Nat Med 12, 452, 2006.

75. Radisic, M., Euloth, M., Yang, L., Langer, R., Freed, L.E., and Vunjak-Novakovic, G. High-density seeding of myocyte cells for cardiac tissue engineering. Biotechnol Bioeng 82, 403, 2003.

76. Tandon, N., Cannizzaro, C., Chao, P.H., Maidhof, R., Marsano, A., Au, H.T., et al. Electrical stimulation systems for cardiac tissue engineering. Nat Protoc 4, 155, 2009.

77. Radisic, M., Malda, J., Epping, E., Geng, W., Langer, R., and Vunjak-Novakovic, G. Oxygen gradients correlate with cell density and cell viability in engineered cardiac tissue. Biotechnol Bioeng 93, 332, 2006. 
78. Radisic, M., Park, H., Chen, F., Salazar-Lazzaro, J.E., Wang, Y., Dennis, R., et al. Biomimetic approach to cardiac tissue engineering: oxygen carriers and channeled scaffolds. Tissue Eng 12, 2077, 2006.

79. Narmoneva, D.A., Vukmirovic, R., Davis, M.E., Kamm, R.D., and Lee, R.T. Endothelial cells promote cardiac myocyte survival and spatial reorganization: implications for cardiac regeneration. Circulation 110, 962, 2004.

80. Shen, Y.H., Shoichet, M.S., and Radisic, M. Vascular endothelial growth factor immobilized in collagen scaffold promotes penetration and proliferation of endothelial cells. Acta Biomater 4, 477, 2008.

81. Ratajska, A., Ciszek, B., and Sowinska, A. Embryonic development of coronary vasculature in rats: corrosion casting studies. Anat Rec 270A, 109, 2003.

82. Rakusan, K., Flanagan, M.F., Geva, T., Southern, J., and Van Praagh, R. Morphometry of human coronary capillaries during normal growth and the effect of age in left ventricular pressure-overload hypertrophy. Circulation 86, 320, 1992.

83. Beltrami, A.P., Barlucchi, L., Torella, D., Baker, M., Limana, F., Chimenti, S., et al. Adult cardiac stem cells are multipotent and support myocardial regeneration. Cell 114, 763, 2003.

84. Shimizu, T., Sekine, H., Yang, J., Isoi, Y., Yamato, M., Kikuchi, A., et al. Polysurgery of cell sheet grafts overcomes diffusion limits to produce thick, vascularized myocardial tissues. FASEB J 20, 708, 2006.

85. Morritt, A.N., Bortolotto, S.K., Dilley, R.J., Han, X., Kompa, A.R., McCombe, D., et al. Cardiac tissue engineering in an in vivo vascularized chamber. Circulation 115, 353, 2007.

86. Naito, H., Melnychenko, I., Didie, M., Schneiderbanger, K., Schubert, P., Rosenkranz, S., et al. Optimizing engineered heart tissue for therapeutic applications as surrogate heart muscle. Circulation 114, I72, 2006.

87. Radisic, M., Fast, V.G., Sharifov, O.F., Iyer, R.K., Park, H., and Vunjak-Novakovic, G. Optical mapping of impulse propagation in engineered cardiac tissue. Tissue Eng Part A 15, 851, 2009.

88. Bursac, N., Loo, Y., Leong, K., and Tung, L. Novel anisotropic engineered cardiac tissues: studies of electrical propagation. Biochem Biophys Res Commun 361, 847, 2007.

89. Radisic, M., Park, H., Shing, H., Consi, T., Schoen, F.J., Langer, R., et al. From the cover: functional assembly of engineered myocardium by electrical stimulation of cardiac myocytes cultured on scaffolds. PNAS 101, 18129, 2004.

90. Radisic, M., Park, H., Martens, T.P., Salazar-Lazaro, J.E., Geng, W., Wang, Y., et al. Pre-treatment of synthetic elastomeric scaffolds by cardiac fibroblasts improves engineered heart tissue. J Biomed Mater Res A 86, 713, 2008.

91. Eschenhagen, T., Zimmermann, W.H., and Kleber, A.G. Electrical coupling of cardiac myocyte cell sheets to the heart. Circ Res 98, 573, 2006.

92. Zimmermann, W.H., Schneiderbanger, K., Schubert, P., Didie, M., Munzel, F., Heubach, J.F., Kostin, S., Neuhuber, W.L., and Eschenhagen, T. Tissue engineering of a differentiated cardiac muscle construct. Circ Res 90, 223, 2002.

93. Segers, V.F.M., and Lee, R.T. Stem-cell therapy for cardiac disease. Nature 451, 937, 2008.

94. Chien, K.R. Regenerative medicine and human models of human disease. Nature 453, 302, 2008.

95. Daley, W.P., Peters, S.B., and Larsen, M. Extracellular matrix dynamics in development and regenerative medicine. J Cell Sci 121, 255, 2008.
96. Lensch, M.W., Daheron, L., and Schlaeger, T.M. Pluripotent stem cells and their niches. Stem Cell Rev 2, 185, 2006.

97. Morrison, S.J., and Spradling, A.C. Stem cells and niches: mechanisms that promote stem cell maintenance throughout life. Cell 132, 598, 2008.

98. Scadden, D.T. The stem-cell niche as an entity of action. Nature 441, 1075, 2006.

99. Freed, L.E., Guilak, F., Guo, X.E., Gray, M.L., Tranquillo, R., Holmes, J.W., et al. Advanced tools for tissue engineering: scaffolds, bioreactors, and signaling. Tissue Eng 12, 3285, 2006.

100. Carrier, R.L., Rupnick, M., Langer, R., Schoen, F.J., Freed, L.E., and Vunjak-Novakovic, G. Perfusion improves tissue architecture of engineered cardiac muscle. Tissue Eng 8, 175, 2002.

101. Baksh, D., Zandstra, P.W., and Davies, J.E. A non-contact suspension culture approach to the culture of osteogenic cells derived from a CD49elow subpopulation of human bone marrow-derived cells. Biotechnol Bioeng 98, 1195, 2007.

102. Ng, Y.L., and Chase, H.A. Novel bioreactors for the culture and expansion of aggregative neural stem cells. Bioprocess Biosyst Eng 31, 393, 2008.

103. Brown, M.A., Iyer, R.K., and Radisic, M. Pulsatile perfusion bioreactor for cardiac tissue engineering. Biotechnol Prog 24, 907, 2008.

104. Isenberg, B.C., Williams, C., and Tranquillo, R.T. Smalldiameter artificial arteries engineered in vitro. Circ Res 98, $25,2006$.

105. O'Cearbhaill, E.D., Punchard, M.A., Murphy, M., Barry, F.P., McHugh, P.E., and Barron, V. Response of mesenchymal stem cells to the biomechanical environment of the endothelium on a flexible tubular silicone substrate. Biomaterials 29, 1610, 2008.

106. Godier, A.F., Marolt, D., Gerecht, S., Tajnsek, U., Martens, T.P., and Vunjak-Novakovic, G. Engineered microenvironments for human stem cells. Birth Defects Res C Embryo Today 84, 335, 2008.

107. Ly, H.Q., Frangioni, J.V., and Hajjar, R.J. Imaging in cardiac cell-based therapy: in vivo tracking of the biological fate of therapeutic cells. Nat Clin Pract Cardiovasc Med Suppl 2, S96, 2008.

108. Schroeder, T. Imaging stem-cell-driven regeneration in mammals. Nature 453, 345, 2008.

109. Hillman, E., and Moore, A. All-optical anatomical coregistration for molecular imaging of small animals using dynamic contrast. Nat Photonics 1, 526, 2007.

110. Shah, B.S., Clark, P.A., Moioli, E.K., Stroscio, M.A., and Mao, J.J. Labeling of mesenchymal stem cells by bioconjugated quantum dots. Nano Lett 7, 3071, 2007.

111. Yamada, T., Yang, J.J., Ricchiuti, N.V., and Seraydarian, M.W. Oxygen consumption of mammalian myocardial cells in culture: measurements in beating cells attached to the substrate of the culture dish. Anal Biochem 145, 302, 1985.

112. Eschenhagen, T., and Zimmermann, W.H. Engineering myocardial tissue. Circ Res 97, 1220, 2005. Erratum in: Circ Res 98(2), e19, 2006 Feb 3.

113. Radisic, M., Park, H., and Vunjak-Novakovic, G. Cardiac tissue engineering. In: Lanza, Langer, Vacanti, eds. Principles of Tissue Engineering, 3rd edition. Boston: Elsevier Academic Press, 2007, pp. 551-568.

114. Shimizu, T., Yamato, M., Isoi, Y., Akutsu, T., Setomaru, T., Abe, K., Kikuchi, A., Umezu, M., and Okano, T. Fabrication of pulsatile cardiac tissue grafts using a novel 3-dimensional cell sheet manipulation technique and temperature-responsive cell culture surfaces. Circ Res 90, e40, 2002. 
115. Ypey, D.L., Clapham, D.E., and DeHaan, R.L. Development of electrical coupling and action potential synchrony between paired aggregates of embryonic heart cells. J Membr Biol 51, 75, 1979.

116. Veenstra, R.D., and DeHaan, R.L. Electrotonic interactions between aggregates of chick embryo cardiac pacemaker cells. Am J Physiol Heart Circ Physiol 250, H453, 1986.

117. Soejima, K.M.D., Negishi, N.P., Nozaki, M.M.D., and Sasaki, K.M.D. Effect of cultured endothelial cells on angiogenesis in vivo. Plastic Reconstr Surg 101, 1552, 1998.

118. Masuda, S., Shimizu, T., Yamato, M., and Okano, T. Cell sheet engineering for heart tissue repair. Adv Drug Deliv Rev 60, 277, 2008.

119. Fink, C., Ergun, S., Kralisch, D., Remmers, U.T.E., Weil, J., and Eschenhagen, T. Chronic stretch of engineered heart tissue induces hypertrophy and functional improvement. FASEB J 14, 669, 2000.

120. Zimmermann, W.-H., Didie, M., Wasmeier, G.H., Nixdorff, U., Hess, A., Melnychenko, I., Boy, O., Neuhuber, W.L., Weyand, M., and Eschenhagen, T. Cardiac grafting of engineered heart tissue in syngenic rats. Circulation 106, I-151, 2002.

121. Boublik, J., Park, H., Radisic, M., Tognana, E., Chen, F., Pei, M., et al. Mechanical properties and remodeling of hybrid cardiac constructs made from heart cells, fibrin, and biodegradable, elastomeric knitted fabric. Tissue Eng 11, 1122, 2005.

122. Wang, Y., Ameer, G.A., Sheppard, B.J., and Langer, R. A tough biodegradable elastomer. Nat Biotechnol 20, 602, 2002.

123. Radisic, M., Deen, W., Langer, R., and Vunjak-Novakovic, G. Mathematical model of oxygen distribution in engineered cardiac tissue with parallel channel array perfused with culture medium containing oxygen carriers. Am J Physiol Heart Circ Physiol 288, H1278, 2005.

124. Kamkin, A., Kiseleva, I., and Isenberg, G. Activation and inactivation of a non-selective cation conductance by local mechanical deformation of acutely isolated cardiac fibroblasts. Cardiovasc Res 57, 793, 2003.
125. Kamkin, A., Kiseleva, I., Lozinsky, I., and Scholz, H. Electrical interaction of mechanosensitive fibroblasts and myocytes in the heart. Basic Res Cardiol 100, 337, 2005.

126. Komuro, I., Kaida, T., Shibazaki, Y., Kurabayashi, M., Katoh, Y., Hoh, E., et al. Stretching cardiac myocytes stimulates protooncogene expression. J Biol Chem 265, 3595, 1990.

127. Sadoshima, J., and Izumo, S. The cellular and molecular response of cardiac myocytes to mechanical stress. Annu Rev Physiol 59, 551, 1997.

128. Zak, R. Development and proliferative capacity of cardiac muscle cells. Circ Res 35, 17, 1974.

129. Vandenburgh, H.H., Solerssi, R., Shansky, J., Adams, J.W., and Henderson, S.A. Mechanical stimulation of organogenic cardiomyocyte growth in vitro. Am J Physiol Cell Physiol 270, C1284, 1996.

130. Au, H.T., Cheng, I., Chowdhury, M.F., and Radisic, M. Interactive effects of surface topography and pulsatile electrical field stimulation on orientation and elongation of fibroblasts and cardiomyocytes. Biomaterials 28, 4277, 2007.

131. Baudino, T.A., Carver, W., Giles, W., and Borg, T.K. Cardiac fibroblasts: friend or foe? Am J Physiol Heart Circ Physiol 291, H1015, 2006.

Address correspondence to: Gordana Vunjak-Novakovic, Ph.D. Department of Biomedical Engineering

Columbia University 622 W 168th St. VC 12-234

New York, NY 10032

E-mail: gv2131@columbia.edu

Received: May 28, 2009 Accepted: August 20, 2009

Online Publication Date: October 13, 2009 
